\title{
Organic Membranes for Selectivity Enhancement of Metal Oxide Gas Sensors
}

\author{
Thorsten Graunke, ${ }^{1,2}$ Katrin Schmitt, ${ }^{3}$ and Jürgen Wöllenstein ${ }^{1,3}$ \\ ${ }^{1}$ Laboratory for Gas Sensors, Department of Microsystems Engineering-IMTEK, University of Freiburg, \\ Georges-Koehler-Allee 102, 79110 Freiburg, Germany \\ ${ }^{2}$ ams Sensor Solutions Germany GmbH, Gerhard-Kindler-Strasse 8, 72770 Reutlingen, Germany \\ ${ }^{3}$ Fraunhofer-Institute for Physical Measurement Techniques IPM, Heidenhofstraße 8, 79110 Freiburg, Germany
}

Correspondence should be addressed to Thorsten Graunke; thorsten.graunke@ams.com

Received 1 September 2015; Accepted 19 October 2015

Academic Editor: Sheikh Akbar

Copyright (C) 2016 Thorsten Graunke et al. This is an open access article distributed under the Creative Commons Attribution License, which permits unrestricted use, distribution, and reproduction in any medium, provided the original work is properly cited.

\begin{abstract}
We present the characterization of organic polyolefin and thermoplastic membranes for the enhancement of the selectivity of metal oxide (MOX) gas sensors. The experimental study is done based on theoretical considerations of the membrane characteristics. Through a broad screening of dense symmetric homo- and copolymers with different functional groups, the intrinsic properties such as the mobility or the transport of gases through the matrix were examined in detail. A subset of application-relevant gases was chosen for the experimental part of the study: $\mathrm{H}_{2}, \mathrm{CH}_{4}, \mathrm{CO}, \mathrm{CO}_{2}, \mathrm{NO}_{2}$, ethanol, acetone, acetaldehyde, and water vapor. The gases have similar kinetic diameters and are therefore difficult to separate but have different functional groups and polarity. The concentration of the gases was based on the international indicative limit values (TWA, STEL). From the results, a simple relationship was to be found to estimate the permeability of various polar and nonpolar gases through gas permeation (GP) membranes. We used a broadband metal oxide gas sensor with a sensitive layer made of tin oxide with palladium catalyst $\left(\mathrm{SnO} \mathrm{S}_{2}: \mathrm{Pd}\right)$. Our aim was to develop a low-cost symmetrical dense polymer membrane to selectively detect gases with a MOX sensor.
\end{abstract}

\section{Introduction}

The reliable detection of toxic and flammable gases is of high importance in many fields of daily life, for example, surveillance of chemical processes, or in the event of fires or disasters. The early detection of toxic gas concentrations can save lives and aid in taking appropriate countermeasures. A variety of different gas sensing technologies is used to detect these gases. The choice of the right technology depends on the required sensitivity, selectivity, and, last but not least, the costs. A gas sensor is generally composed of a receptor (probe) and a transducer (signal transducer). If the sensor comes with integrated signal processing, it is usually called "smart sensor." Depending on the environment and application, different gas sensing technologies are available, which are classified according to their physicochemical functional principle (IUPAC 1991) into optical, electrochemical, conductivity, ultrasonic, magnetic, thermometric, and mass-sensitive sensors [1-5]. In reality, all sensing technologies are more or less prone to some drift effects, susceptible to interfering gases, vapors, or other uncontrollable memory effects. These effects reduce sensitivity, but also selectivity. One way to increase the selectivity of gas sensors in general is the use of passive filter materials [6].

Passive filter materials are in most cases flat, semipermeable membranes that are permeable to at least one material component. The membranes are characterized by the size or molecular weight of the transmitted component, the driving force, the principle of separation, and the present state of aggregation. Filters for microfiltration (MF), ultrafiltration (UF), and nanofiltration (NF) have pore diameters $(x)$ of $x>$ $100 \mathrm{~nm}, 10 \mathrm{~nm}<x<100 \mathrm{~nm}$, and $1<x<10 \mathrm{~nm}$. The states of aggregation to be separated are liquid/liquid, solid/liquid, or solid/gaseous. Usually the separation is accomplished by sieve mechanisms or sorption + diffusion mechanisms. The driving force is a pressure difference or a difference in 
the chemical potential. In the separation of small molecules with diameters of less than $1 \mathrm{~nm}$, the reverse osmosis (RO), the diffusion dialysis (DD), or electrodialysis (ED) is used as the membrane process for the physical state liquid/liquid. The separation mechanism is based on a sorption + diffusion in the RO and DD. In the ED, the mechanism is based on electrophoretic mobility. The driving force is the difference of the chemical potential (in RO), a concentration difference (in DD), or a difference in electrical potential (in ED). If the physical state is liquid/gas, the method of choice is pervaporation $(\mathrm{PV})$. The material separation proceeds via a sorption + diffusion mechanism. The driving force is a partial pressure difference. For separation of gaseous components (gas/gas), vapor permeation (VP) and gas permeation (GP) are used. The driving force here is a partial pressure just as in pervaporation. The mechanism is based on sorption + diffusion. In the VP the gases are under standard conditions $\left(21^{\circ} \mathrm{C}, 1 \mathrm{bar}\right)$ in liquid form and in gaseous form at the GP. For the membrane method of VP and GP a variety of commercial and in-process membranes is available. Interesting for use as a selective filter in the gas sensors are synthetic, solid membrane materials. These comprise organic, inorganic, or heterogeneous membranes. Heterogeneous membranes consist of a combination of organic and inorganic materials.

The organic polymer membranes are in a rubbery-elastic, hard-elastic, or glassy state, depending on the glass transition temperature. The degree of crystallinity is amorphous, semicrystalline, or ideal crystalline. For the separation of gases only dense polymer membranes or polymers having intrinsic microporosity (PIM) can be used [7]. In dense glassy polymer membranes the influence of diffusion is high compared to the sorption. For this reason, preferably small molecules are transported, independently of the polymer. The permeability decreases in the order $\mathrm{C}_{3} \mathrm{H}_{8}<\mathrm{CH}_{4}<\mathrm{N}_{2}<$ $\mathrm{CO}<\mathrm{O}_{2}<\mathrm{CO}_{2}<\mathrm{He}<\mathrm{H}_{2}<\mathrm{H}_{2} \mathrm{O}$. In rubbery polymers the solubility determines the permeability [8]. The permeability is significantly higher and preferably large molecules are transported. In elastomeric polymers, the permeability decreases usually in the order $\mathrm{N}_{2}<\mathrm{He}<\mathrm{O}_{2}<\mathrm{H}_{2}<$ $\mathrm{CH}_{4}<\mathrm{CO}_{2}<\mathrm{C}_{3} \mathrm{H}_{8}<\mathrm{H}_{2} \mathrm{O}$ [9]. This results in an inverse correlation. Highly permeable elastomeric symmetric polymers are usually not very selective, while glassy symmetric polymers have a high selectivity and at the same time a low permeability. When modified, polymers can be adapted to specific applications. Thus, a polymer can be functionalized or its polarity, that is, hydrophobicity/hydrophilicity, can be altered by a chemical modification. In addition to a modification of the membrane material by integration of additives to establish block- or comb-copolymers, surface-controlled chemical modifications may be done. One example is fixedside carrier membranes, where suitable carriers are bound in a polymer matrix. By fixing of gas molecules, a facilitated, selective mass transport through the membrane is achieved by hopping mechanisms [10]. Surface chemical modifications can be achieved by adsorption without interfering with the structure ("self-assembly" coatings), by chemically modifying the base material or by using the base material for further functionalization. The morphology of the polymer is not or only minimally changed by derivatization, grafting, or targeted degradation during chemical modification. The physical activation is preferably done by UV radiation or plasma treatment. During functionalization macromolecular functional units are introduced via grafting reactions. This is either a directed coupling by chemical reaction with reactive groups on the surface (covalent "grafting-to") or a heterogeneous radical graft copolymerization with the aid of fixed initiator groups ("grafting from"). Using these functional groups, the surface properties can be optimized [11-14] with regard to polarity, hydrophilicity/hydrophobicity, and the resistance to fouling.

Using asymmetric polymers, the permeability can be increased by a factor of at least fifty, up to one hundred, while maintaining a constant selectivity. Asymmetric polymers consist of a dense barrier layer having a thickness of $0.05-0.5 \mu \mathrm{m}$. The separation layer is stabilized by a porous supporting layer $(30-200 \mu \mathrm{m})$. The pore size increases with distance from the separating layer. They involve integralasymmetric membranes consisting of a polymer, or composite materials in which the active layer and the support layer are manufactured from different materials. In composite materials, the properties of the individual layers can be optimally adapted to a separation problem. Since it is difficult to apply a thin release layer on a porous structure, a smooth highly permeable intermediate layer is often applied. Very thin separation layers are prone to build up pinholes which may result in Knudsen diffusion or an unselective viscous gas flow. Such pinholes can be sealed with a silicone coating. The separation factor is only minimally affected by such a cover layer. An overview of gas-selective polymer membranes is given in $[9,15,16]$ in combination with gas sensors in $[17,18]$.

On the other hand, inorganic membranes for special applications of microfiltration (MF) and ultrafiltration (UF) are now established. Among these are silica-based membranes of high importance [19-23] but also zeolites [24-30]. Other materials involve perovskites $[31,32], \mathrm{Al}_{2} \mathrm{O}_{3}[19,33$, 34], or copper oxide [35]. Compared to polymers, inorganic membranes have the following advantages: the cut-off and separation sharpness can be better controlled. The membranes are characterized by a higher temperature resistance, a lower aging, and better chemical resistance (no membrane swelling). Among symmetric porous inorganic membranes for gas separation, the carbon membrane is important. However, inorganic membranes have the following disadvantages limiting their application as GP membranes: the materials are mostly brittle and require a multilayered structure, which also involves several steps. The production is therefore more expensive than for comparable polymer membranes. Therefore, the membranes are simply too expensive for applications in gas sensor technology. Therefore inorganic membranes are not described here in detail, instead we refer to overviews of gas-selective inorganic membranes given in $[36,37]$.

Another class, the so-called mixed matrix membranes (MMM), consists of a combination of inorganic and organic materials [38-40]. The selectivity and the permeability of the membrane can be calculated in advance from the data of the homogeneous materials. The company Creavis provides flexible ceramic flat membranes under the trade name Creafilter. This membrane consists of a support made of metal 
or plastic fabrics on which ceramic particles are applied in an asymmetric structure. Pore sizes in the separation layer can now be realized from 0.5 to $5 \mathrm{~nm}$. A further possibility is the incorporation of inorganic particles into a polymer matrix, forming the separation layer. Inorganic materials used are molecular sieves (zeolites such as LTA, AlPO, SAPO, SSZ-13, and ZSM-5), porous metals (MOM: metal organic material), pyrolyzed polymers (CMS: carbon molecular sieve), mesoporous molecular sieves, silicates, metal oxides, activated carbon, nanotubes (NT: nanotube), or also liquids [41]. This overview is adapted from [42-44]. Further details on GP membranes can be found in [45-51].

Due to the industrial applications of GP membranes, primarily the binary gas mixtures $\mathrm{O}_{2} / \mathrm{N}_{2}, \mathrm{~N}_{2} / \mathrm{CH}_{4}, \mathrm{SO}_{2} / \mathrm{CH}_{4}$, $\mathrm{H}_{2} / \mathrm{N}_{2}, \mathrm{He} / \mathrm{N}_{2}, \mathrm{CO}_{2} / \mathrm{N}_{2}, \mathrm{CO}_{2} / \mathrm{CH}_{4}, \mathrm{H}_{2} / \mathrm{CO}_{2}, \mathrm{SO}_{2} / \mathrm{CO}_{2}$, $\mathrm{H}_{2} / \mathrm{CO}$, and $\mathrm{H}_{2} / \mathrm{CH}_{4}$ are of interest. In connection with carbon membranes, occasionally separation factors for the binary mixtures $\mathrm{C}_{2} \mathrm{H}_{4} / \mathrm{C}_{2} \mathrm{H}_{6}, \mathrm{H}_{2} / \mathrm{n}-\mathrm{C}_{4} \mathrm{H}_{10}, \mathrm{C}_{3} \mathrm{H}_{6} / \mathrm{C}_{3} \mathrm{H}_{8}$ can be found. In many applications, the influence of air humidity on the performance of polymers is of significance. So the permeability for $\mathrm{CO}_{2}$ and $\mathrm{CH}_{4}$ from Matrimid and polysulfone (PS) in humid air decreases greatly [52]. For the separation of volatile organic compounds (VOC), the methods of pervaporation (PV) and vapor permeation (VP) may be used. The substances to be separated are in a liquid or vaporous state, respectively. The separation is determined as in the GP mainly by the interaction of the component with the membrane. Therefore, the most important factors are the solubility and diffusion. For all three methods, the same membranes can be used. Hydrophilic membranes are used for the vapor permeation and for the separation of polar components. Applications are the drying of ethanol $\left(\mathrm{H}_{2} \mathrm{O} / \mathrm{EtOH}\right)$ or methane $\left(\mathrm{H}_{2} \mathrm{O} / \mathrm{CH}_{4}\right)$. Organophilic membranes have a high affinity towards nonpolar substances. An important application is the removal of VOCs from water. Among these VOCs are toluene, n-butanol, n-propanol, ethanol, acetone, and methylene chloride. For the separation of organic mixtures (VOC/gas), less highly crosslinked hydrophilic membranes such as poly(1-trimethylsilyl1-propyne) (PTMSP), polyoctylmethylsiloxane (POMS), and polydimethylsiloxane (PDMS) are used [53-58].

Despite the enormous amount of polymer membranes that are available and the many new developments in the field of membrane GP, only 8 to 9 polymers have a market share of $90 \%$. These are polyimide (PI), polysulfone (PS), polyaramid (PA), polycarbonate (PC), cellulose acetate (CA), polyphenylene oxide (PPO), and fluoropolymers. Important representatives of the fluoropolymers are polytetrafluoroethylene (PTFE), polychlorotrifluoroethylene (ECTFE), and fluorinated ethylene-co-propylene (FEP). The only representatives of the elastomeric polymers are silicones like PTMSP, PDMS, and POMS. These polymers are used in the following industrial separation processes. PI: $\left(\mathrm{H}_{2} / \mathrm{CO}\right),\left(\mathrm{H}_{2} / \mathrm{CH}_{4}\right),\left(\mathrm{O}_{2} / \mathrm{N}_{2}\right),\left(\mathrm{CO}_{2} / \mathrm{N}_{2}\right)$, $\left(\mathrm{CO}_{2} / \mathrm{CH}_{4}\right),\left(\mathrm{H}_{2} \mathrm{O} / \mathrm{CH}_{4}\right),\left(\mathrm{H}_{2} \mathrm{O} /\right.$ Luft); PS: $\left(\mathrm{H}_{2} / \mathrm{N}_{2}\right),\left(\mathrm{O}_{2} / \mathrm{N}_{2}\right)$, $\left(\mathrm{H}_{2} / \mathrm{CO}\right),\left(\mathrm{H}_{2} / \mathrm{CH}_{4}\right) ; \mathrm{PA}:\left(\mathrm{H}_{2} \mathrm{O} / \mathrm{CH}_{4}\right),\left(\mathrm{CO}_{2} / \mathrm{CH}_{4}\right) ;$ PC: $\left(\mathrm{O}_{2} / \mathrm{N}_{2}\right)$; CA: $\left(\mathrm{O}_{2} / \mathrm{N}_{2}\right),\left(\mathrm{H}_{2} \mathrm{O} / \mathrm{CH}_{4}\right),\left(\mathrm{CO}_{2} / \mathrm{CH}_{4}\right),\left(\mathrm{H}_{2} / \mathrm{CH}_{4}\right)$, $\left(\mathrm{H}_{2} / \mathrm{CO}\right),\left(\mathrm{H}_{2} / \mathrm{N}_{2}\right)$; PPO: $\left(\mathrm{O}_{2} \mathrm{~N}_{2}\right),\left(\mathrm{CO}_{2} / \mathrm{CH}_{4}\right)$; fluoropolymers: $\left(\mathrm{CO}_{2} / \mathrm{CH}_{4}\right),\left(\mathrm{N}_{2} / \mathrm{CH}_{4}\right)$; silicones: $\left(\mathrm{H}_{2} / \mathrm{CO}\right),\left(\mathrm{H}_{2} / \mathrm{CH}_{4}\right)$,
$\left(\mathrm{O}_{2} / \mathrm{N}_{2}\right),\left(\mathrm{N}_{2} / \mathrm{CH}_{4}\right)$, (VOC/Gas). The first gas listed has the highest permeability through the polymer membrane $[9,16$, $48,55,59]$.

In our study we investigated the permeability of gases including $\mathrm{H}_{2}, \mathrm{CO}, \mathrm{CO}_{2}, \mathrm{NO}_{2}$, methane, ethanol, acetone, acetaldehyde, and moisture through low-cost, symmetrical polymeric materials having a diameter of less than $6.4 \mathrm{~mm}$. Due to the small diameter the membranes can be directly integrated into the metal caps of conventional TO sockets. The mass transfer takes place at room temperature and without partial pressure. The permeate is not removed. Through a broad screening of dense symmetric homo- and copolymers with different functional groups, the intrinsic properties such as the mobility or the transport of gases through the matrix were examined in detail. The gases have similar kinetic diameters and are therefore difficult to separate but have different functional groups and polarity. The concentration of gases is based on the international indicative limit values (TWA, STEL). From the results, a simple relationship is to be found to estimate the permeability of various polar and nonpolar gases through GP membranes. We used a broadband metal oxide gas sensor with a sensitive layer made of $\mathrm{SnO}_{2}: \mathrm{Pd}$. Our aim is to develop a low-cost symmetrical dense polymer membrane to selectively detect gases with a MOX sensor. Although many studies exist on the investigation of single polymeric membranes for selectivity enhancement of sensors, we believe that this is the first study to systematically compile all relevant polymers for this application. The use of the same experimental conditions throughout the study enables us to compare the different polymers and understand the characteristics and mechanisms leading to their separation properties.

\section{Materials and Methods}

2.1. Polyolefins and Thermoplastics. In this study, polyolefins and thermoplastic polycondensates were tested for their separation properties. The structures of the polymers are shown in Figure 1. From the group of polyolefins we used membranes made of polyethylene (PE), low density polyethylene (LDPE), high density polyethylene (HDPE), and graphite filling ( $\mathrm{PE}+$ graphite), as well as polypropylene (PP) and poly-4methylpentene-1 (PMP). These materials are characterized by high chemical resistance, low density, and low water vapor permeability. $\mathrm{PE}$ is a nonpolar, partially crystalline thermoplastic. Due to the diversity in structural composition such as chain length, molecular weight, or degree of branching, the various PE grades differ in their properties. LDPE is a widely branched homopolymer containing both short- and long-chain branches and thus having an enlarged molecular distance compared to other PE types. This results in crystallization degrees between $40 \%$ and $50 \%$ and a density of $0.92 \mathrm{~g} / \mathrm{cm}^{3}$.

The crystalline melting point is between $105^{\circ} \mathrm{C}$ and $110^{\circ} \mathrm{C}$. The water intake is low with $0.015 \%$. In LDPE two glass transitions are observed at $-110^{\circ} \mathrm{C}$ and $-10^{\circ} \mathrm{C}$. The continuous operating temperature is between $50^{\circ} \mathrm{C}$ and $90^{\circ} \mathrm{C}$, the lowest of all investigated polymer membranes, and still adequate for use in gas sensors. HDPE is made up largely of linear 


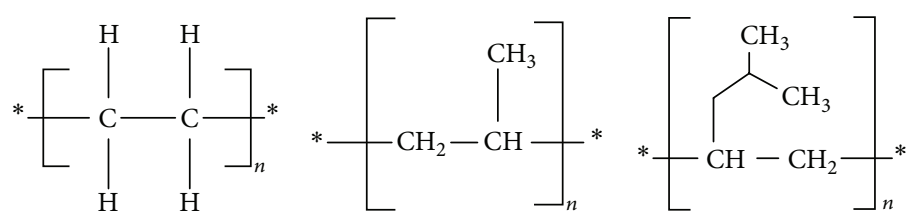

(a)

(b)

(c)<smiles>Cc1ccc(C(C)(C)c2ccc(OC(=O)OC(C)(C)C)cc2)cc1</smiles>

(d)<smiles>CC(C)(C)OCCOC(=O)c1cccc(C(=O)C(C)(C)C)c1</smiles>

(e)<smiles>CC(C)(C)OCCOC(=O)c1ccc2cc(C(=O)C3(C)COC3)ccc2c1</smiles>

(f)

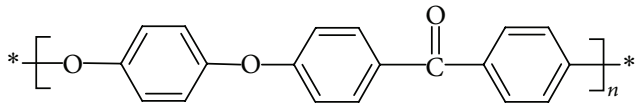

(g)

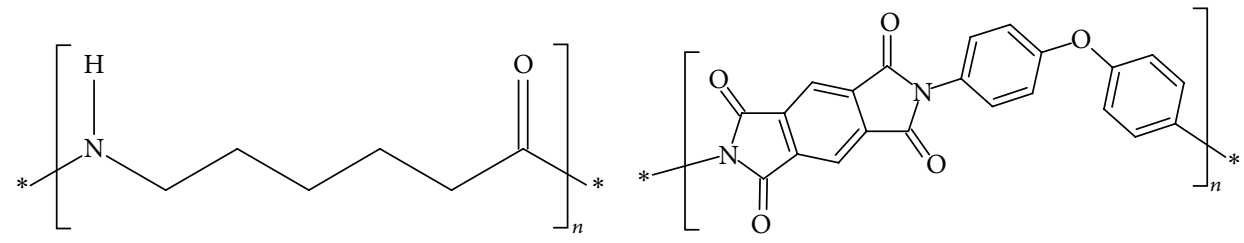

(h)

(i)<smiles>CC(C)(c1ccc(Oc2ccc3c(c2)C(=O)N(c2ccc(C[18F])cc2)C3=O)cc1)c1ccc(Oc2ccc3c(c2)C(=O)N(C(C)(C)C)C3=O)cc1</smiles>

(j)

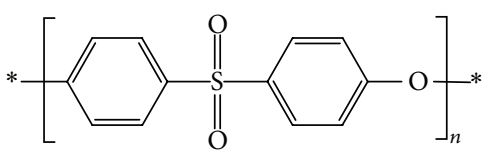

(k)

FIGURE 1: Molecular configurations of homopolymers used: (a) polyethylene (PE), (b) polypropylene (PP), (c) poly-4-methylpentene-1 (PMP), (d) polycarbonate (PC), (e) polyethylenterephthalat (PET), (f) polyethylene naphthalate (PEN), (g) polyetheretherketone (PEEK), (h) polyamide (PA6), (i) polyimide (PI), (j) polyetherimide (PEI), and (k) polyethersulfone (PES).

macromolecules having a low degree of branching. This leads to a higher degree of crystallization of $60 \%$ to $80 \%$ and, accordingly, a higher density of $0.95 \mathrm{~g} / \mathrm{cm}^{3}$. With increasing density, the swelling and permeability decrease. HDPE shows practically no water absorption $(<0.01 \%)$. In contrast, the crystalline melting point $\left(130-135^{\circ} \mathrm{C}\right)$ rises as well as the continuous operating temperature $\left(55-120^{\circ} \mathrm{C}\right)$. Both HDPE and LDPE have a glass transition around $-110^{\circ} \mathrm{C}$. The PE membrane with graphite filling has a density of $0.96 \mathrm{~g} / \mathrm{cm}^{3}$. The addition of graphite increases the chemical resistance. PP is a semicrystalline, nonpolar polymer.

The degree of crystallization is essentially determined by the tacticity of the macromolecular chains. The isotactic PP has due to the regular arrangement of the methyl side groups the highest degree of crystallinity (60-70\%). PP shows crystal modifications of the $\alpha_{-}^{-}, \beta$-, and $\gamma$-modification and mesomorphic (smetic) forms. In the crystalline domains, the macromolecules are in the form of folded chains as lamellae. The water uptake is only minimally higher than that of HDPE with $<0.05$. The density is a result of the increased distances by $-\mathrm{CH}_{4}$ side group with $0.9 \mathrm{~g} / \mathrm{cm}^{3}$ less than for LDPE. The statistically measured glass transition temperature is $-10^{\circ} \mathrm{C}$. The crystallite melting range is from $160^{\circ} \mathrm{C}$ to $168^{\circ} \mathrm{C}$. PP films have an upper continuous operating temperature of $100^{\circ} \mathrm{C}$. $\mathrm{PMP}$ is a semicrystalline, largely isotactic thermoplastic. The bulky side group leads to a crystalline melting point of $236^{\circ} \mathrm{C}$ and to an unusually low density of $0.83 \mathrm{~g} / \mathrm{cm}^{3}$. PMP has the lowest density of all thermoplastics. At room temperature, the amorphous domains are denser. At a temperature of $60^{\circ} \mathrm{C}$ both states have the same density. Due to the different coefficients of thermal expansion, there is a cavity forming between the amorphous and crystalline areas. The water 
absorption is below $0.01 \%$. PMP has two glass transitions at $-55^{\circ} \mathrm{C}$ and between $+50^{\circ} \mathrm{C}$ and $+60^{\circ} \mathrm{C}$. The upper continuous operating temperature is $120^{\circ} \mathrm{C}$ [60-62].

The second group which was examined with respect to their separation properties is thermoplastic polycondensates. In this group the membranes are made of polycarbonate (PC), polyethylene terephthalate (PET), polyethylene naphthalate (PEN), polyether ether ketone (PEEK), polyamide (PA6), polyimide (PI), polyetherimide (PEI), and polyethersulfone (PES). PC, PET, and PEN are thermoplastic polyesters. PC is a purely amorphous, linear thermoplastic. The ester groups (-COOR) are polar and are separated by aromatic groups. The polarity leads to water absorption of 0.15 to $0.35 \%$. The angled and bulky repeating unit restricts the mobility of the macromolecules. This leads to a high glass transition temperature of $148^{\circ} \mathrm{C}$. The operating temperature is $125^{\circ} \mathrm{C}$. The density is $1.2 \mathrm{~g} / \mathrm{cm}^{3}$. Films can be cast with a minimum thickness of $2 \mu \mathrm{m}$ from solutions. PET crystallizes very slowly. Therefore, it may be amorphous or semicrystalline with a degree of crystallization of $30 \%$ to $40 \%$. The average glass transition temperature is $98^{\circ} \mathrm{C}$. The melting temperature is $250-265^{\circ} \mathrm{C}$. The water absorption is $0.1 \%$ higher than that of the polyolefins, however, lower than that of PC. The density varies between $1.3 \mathrm{~g} / \mathrm{cm}^{3}$ in the amorphous and $1.4 \mathrm{~g} / \mathrm{cm}^{3}$ in the semicrystalline state. The operating temperature is between $115^{\circ} \mathrm{C}$ and $150^{\circ} \mathrm{C}$. In PEN the polar ester groups (-COOR) are separated from each other by bicyclic nonpolar aromatic groups (naphthalene). As a result, the crystalline melting temperature is increased to $270^{\circ} \mathrm{C}\left(250^{\circ} \mathrm{C}\right.$ to $265^{\circ} \mathrm{C}$ in PET), the glass transition temperature is higher at $122^{\circ} \mathrm{C}$ (PET: $98^{\circ} \mathrm{C}$ ), and the continuous operating temperature rises to $155^{\circ} \mathrm{C}\left(\mathrm{PET} 115^{\circ} \mathrm{C}\right.$ to $\left.150^{\circ} \mathrm{C}\right)$. By quenching in ice water, a low degree of crystallization of $\approx 5 \%$ is achieved. As a film, PEN is amorphous and biaxially oriented and has a density of $1.36 \mathrm{~g} / \mathrm{cm}^{3}$. PEN shows, compared to PET, higher gas tightness and improved mechanical properties, as well as greater resistance to hydrolysis and chemicals. The water absorption is $0.4 \%$ significantly higher than in PC and PET.

By a direct linear linking of aromatics via ether and carbonyl (ketone) bridges (e.g., in PEEK), via imide or ether bridges (e.g., in PI and PEI), or via ether or sulfone bridges (e.g., in PES), polymers are obtained with very high thermal stability and improved chemical and physical properties. This is because the binding energy is higher than that of simple $\mathrm{CC}$ chains. PEEK belongs to the group of aromatic polyether ketones. With an increasing number of ether groups (flexibility) in polyether ketones, the glass transition point and melting point decrease $(\mathrm{PEEEK}>\mathrm{PEEK}>\mathrm{PEK}=\mathrm{PEEKK}$ $>$ PEKEKK $>$ PEKK). The glass transition temperature of PEEK is $143^{\circ} \mathrm{C}$. The crystalline melting point is $334^{\circ} \mathrm{C}$. The density varies between $1.26 \mathrm{~g} / \mathrm{cm}^{3}$ in the amorphous and $1.32 \mathrm{~g} / \mathrm{cm}^{3}$ in the semicrystalline state. PEEK has a maximum degree of crystallization of $48 \%$. Thin films made of PEEK are amorphous with a density of $1.26 \mathrm{~g} / \mathrm{cm}^{3}$. The water absorption is $0.1 \%$ to $0.3 \%$ lower than that of PEN. PEEK has a very high continuous operating temperature of $250^{\circ} \mathrm{C}$ and is one of the high-performance plastics. PA 6 belongs to the group of aliphatic polyamides. The properties of polyamides are essentially determined by the carboxamides and the number of methylene groups between the carboxamides. A distinction is made between two types, the AB-polyamides and the AABB polyamides. PA6 is an AB polyamide. The number of $-\mathrm{CH}_{2}$ - groups between recurring carboxamide is five. In the linear PA6 macromolecules, only every second functional group allows a hydrogen bond. The density is $1.13 \mathrm{~g} / \mathrm{cm}^{3}$ and the water absorption $2.7 \%$. With an increasing number of methyl groups, the density and water absorption decrease in polyamides (e.g., PA6 > PA11 > PA12). The degree of crystallization is $50 \%$ to $60 \%$. The crystalline melting point of PA6 is $230^{\circ} \mathrm{C}$. In general, polyamides with an even number of $-\mathrm{CH}_{2}$ - groups melt at higher temperatures than those with an odd number (e.g., PA11 > PA12). The operating temperature is between $80^{\circ} \mathrm{C}$ and $100^{\circ} \mathrm{C}$. The glass transition in PA6 is highly moisture-dependent. Dry PA6 has a glass transition temperature of $60^{\circ} \mathrm{C}$. With a moisture content of $3.5 \%$, the transition temperature shifts to $5^{\circ} \mathrm{C}$ and at $10 \%$ even to $-15^{\circ} \mathrm{C}$. Polyamides are highly polar because of the $-\mathrm{NH}$ and $>\mathrm{C}=\mathrm{O}$ groups.

In the first stage of manufacture, the PI macromolecules are in a chain form, thus linear without cross-links. In the second reaction stage (cyclizing condensation polymerization), however, often cross-links form. The structure is therefore linear or cross-linked (thermoset), amorphous, and polar. The monomer consists of an imide and a phenol group. The thready arranged macromolecules, which consist primarily of aromatic and heterocyclic ring compounds, are tightly arranged. This results in a continuous operating temperature of $250^{\circ} \mathrm{C}$, a high stiffness and hardness, a satisfactory resistance to chemicals and water, and high flame retardancy. PI is not meltable (carbonization at $800^{\circ} \mathrm{C}$ ). The glass transition temperature is between 250 and $270^{\circ} \mathrm{C}$. The density of PI is $1.42 \mathrm{~g} / \mathrm{cm}^{3}$. PEI is a linear, amorphous thermoplastic and, like PI, significantly polar. The two ether bridges in the monomeric building block of PEI cause increased flexibility. This leads to a reduction of the continuous operation temperature to $170^{\circ} \mathrm{C}$ to $200^{\circ} \mathrm{C}$ (for comparison: PI has $250^{\circ} \mathrm{C}$ ); the glass transition temperature is $215^{\circ} \mathrm{C}$ (PI: $250^{\circ} \mathrm{C}$ to $270^{\circ} \mathrm{C}$ ) and the density is $1.27 \mathrm{~g} / \mathrm{cm}^{3}$ (PI: $1.42 \mathrm{~g} / \mathrm{cm}^{3}$ ). The water absorption remains virtually unchanged at $0.25 \%$. PES is a member of the so-called polyarylsulfones. PES contains a sulfone $\left(-\mathrm{SO}_{2}-\right)$ and in the 1,4 position linked phenyl rings and an ether linkage. PES is amorphous and substantially polar because of diphenyl sulfone. The bulky structure prevents any formation of crystals in the melt. The aromatic compounds in PES lead to a high continuous operating temperature of $180^{\circ} \mathrm{C}$ to $220^{\circ} \mathrm{C}$. Due to ether groups the polymer chain is more flexible. Thereby, the glass transition temperature is reduced compared to polysulfonyl1,4-phenylene to $225^{\circ} \mathrm{C}$. The density is $1.37 \mathrm{~g} / \mathrm{cm}^{3}$. With $0.4 \%$ to $1 \%$ PES shows the highest water consumption of all polymers investigated. Characteristic properties of PES are high strength, stiffness, hardness, and high resistance to chemicals and hydrolysis [63-68]. The polyolefins and thermoplastic polycondensates were obtained from Goodfellow (GF) and Reichelt Chemietechnik (RCT). These companies provide physical and chemical data on their polymers $[69,70]$. 
TABLE 1: Selected structural, thermal, and mechanical properties of the homopolymers used in our study. dc refers to the degree of crystallinity, the glass transition temperature is $T_{G}, T_{M}$ is the crystallite melting point, $T_{\mathrm{CO}}$ is the continuous operating temperature, and WA is water absorption in $24 \mathrm{~h}$ based on weight percent, the density $\rho$, and $\Delta z$ the thickness of the membrane sheet. Adapted from data sheets of the suppliers Goodfellow (GF) and Reichelt Chemietechnik (RCT) [69, 70].

\begin{tabular}{|c|c|c|c|c|c|c|c|}
\hline Polymer & Structure at $R T\left(21^{\circ} \mathrm{C}\right)$ & $T_{G}\left[{ }^{\circ} \mathrm{C}\right]$ & $T_{\mathrm{KS}}\left[{ }^{\circ} \mathrm{C}\right]$ & $T_{\mathrm{DG}}\left[{ }^{\circ} \mathrm{C}\right]$ & WA [24 h, m\%] & $\rho\left[\mathrm{g} / \mathrm{cm}^{3}\right]$ & $\Delta z[\mu \mathrm{m}]$ \\
\hline LDPE & $\begin{array}{l}\text { Partially crystalline } \\
\quad \text { (dc 40-50\%) }\end{array}$ & $\begin{array}{l}<-110 \\
-10\end{array}$ & 105-110 & $50-90$ & $<0,015$ & 0,92 & $\begin{array}{c}10 \\
(\mathrm{GF})\end{array}$ \\
\hline HDPE & $\begin{array}{l}\text { Partially crystalline } \\
\quad \text { (dc 70-80\%) }\end{array}$ & $<-110$ & $130-135$ & $55-120$ & $<0,01$ & 0,95 & $\begin{array}{c}10 \\
(\mathrm{GF})\end{array}$ \\
\hline $\mathrm{PE}+$ graphite & Partially crystalline & - & - & - & - & 0,96 & $\begin{array}{c}80 \\
(\mathrm{RCT})\end{array}$ \\
\hline PP & $\begin{array}{l}\text { Partially crystalline } \\
\quad \text { (dc 60-70\%) }\end{array}$ & -15 & $160-168$ & 100 & $<0,05$ & 0,9 & $\begin{array}{c}10 \\
(\mathrm{RCT})\end{array}$ \\
\hline PMP & $\begin{array}{l}\text { Partially crystalline } \\
\text { (dc 65\%) }\end{array}$ & $-55 ; 50$ & 236 & 120 & $<0,01$ & 0,83 & $\begin{array}{c}50 \\
(\mathrm{GF})\end{array}$ \\
\hline PC & Amorphous & 148 & - & 125 & $0,15-0,35$ & 1,2 & $\begin{array}{c}20 \\
(\mathrm{RCT})\end{array}$ \\
\hline PET & $\begin{array}{c}\text { Amorphous or partially } \\
\text { crystalline } \\
\text { (dc 30-40\%) }\end{array}$ & 98 & $250-265$ & $115-150$ & 0,1 & $\begin{array}{c}\text { 1,3 (amorphous) } \\
1,4 \text { (crystalline) }\end{array}$ & $\begin{array}{c}13 \\
(\mathrm{GF})\end{array}$ \\
\hline PEN & $\begin{array}{l}\text { Amorphous or partially } \\
\text { crystalline } \\
(\mathrm{dc} \approx 5 \%)\end{array}$ & 122 & 267 & 155 & 0,4 & 1,36 & $\begin{array}{c}12 \\
(\mathrm{GF})\end{array}$ \\
\hline PEEK & $\begin{array}{l}\text { Amorphous or partially } \\
\text { crystalline } \\
(\mathrm{dc} \leq 48 \%)\end{array}$ & 143 & 334 & 250 & $0,1-0,3$ & $\begin{array}{c}\text { 1,26 (amorphous) } \\
1,32 \text { (crystalline) }\end{array}$ & $\begin{array}{c}12 \\
(\mathrm{GF})\end{array}$ \\
\hline PA6 & $\begin{array}{l}\text { Partially crystalline } \\
\quad \text { (dc 50-60\%) }\end{array}$ & $\begin{array}{c}-8 ; 28 \\
55\end{array}$ & 230 & $80-100$ & 2,7 & 1,13 & $\begin{array}{c}15 \\
(\mathrm{GF})\end{array}$ \\
\hline PI & Amorphous & $250-270$ & - & 250 & $0,2-2,9$ & 1,42 & $\begin{array}{c}8 \\
(\mathrm{RCT})\end{array}$ \\
\hline PEI & Amorphous & 215 & - & $170-200$ & 0,25 & 1,27 & $\begin{array}{c}25 \\
(\mathrm{GF})\end{array}$ \\
\hline PES & Amorphous & 230 & - & $180-220$ & $0,4-1,0$ & 1,37 & $\begin{array}{c}25 \\
(\mathrm{GF})\end{array}$ \\
\hline
\end{tabular}

These were compared with the literature references. Table 1 gives an overview on the physical and thermal properties of polyolefins and thermoplastic polycondensates necessary for the description of the separation of substances. The selected passive membranes thus meet the following criteria: the membranes can be used in a temperature range from $-20^{\circ} \mathrm{C}$ to at least $+90^{\circ} \mathrm{C}$ and have a sufficiently high chemical resistance. The membrane materials have a similar layer thickness, so that the release properties can be compared. The separation properties of a polymer membrane are significantly determined by their structure (amorphous $\leftrightarrow$ crystalline, branched $\leftrightarrow$ linear), the resulting degree of crystallization, the density (low density is synonymous with large atomic distances), the polarity (polar $\leftrightarrow$ nonpolar), and the water absorption as a measure of the polarity and through the glass transition point and the crystalline melting point. So, for example, the densities of the selected polymer membranes vary between $0.83 \mathrm{~g} / \mathrm{cm}^{3}$ (polymethylpentene) and $1.4 \mathrm{~g} / \mathrm{cm}^{3}$ (polyimide) and the water absorption varies between $<0.01 \%$ (HDPE and PMP, both nonpolar) and $~ 2.7 \%$ (PA6 and PI, both polar). These are commercially available materials and thus potentially low-priced filter materials.
2.2. Solution-Diffusion Model in Polymer Membranes. The mass transport in porous dense polymer membranes is described by the solution-diffusion model. Here the polymer is treated as a real liquid in which dissolved gas molecules diffuse in the direction of a gradient. A measure of the solubility is generally given by the boiling points and critical temperatures of the gas molecules. The mass transfer through a nonporous membrane is therefore equal to the product of concentration, mobility, and a driving force:

$$
\text { Flow }=\text { concentration } \cdot \text { mobility } \cdot \text { driving force }
$$

The mobility of gases within a polymer structure depends on the size of the gas molecules and the membrane properties such as the glass transition temperature $\left(T_{G}\right)$ and the free volume $\left(V_{f}^{m}\right)$. The driving force for mass transfer is the gradient of the chemical potential within the membrane phase $-d \mu_{i} / d z$, where $z$ is in the direction perpendicular to the membrane surface. The driving force is a function of the thermodynamic quantities: mole fraction $\left(X_{i}\right)$, pressure $\left(p_{i}\right)$, and temperature $(T)$ in the outer permeate and feed phase. The concentration depends on the partition equilibrium 


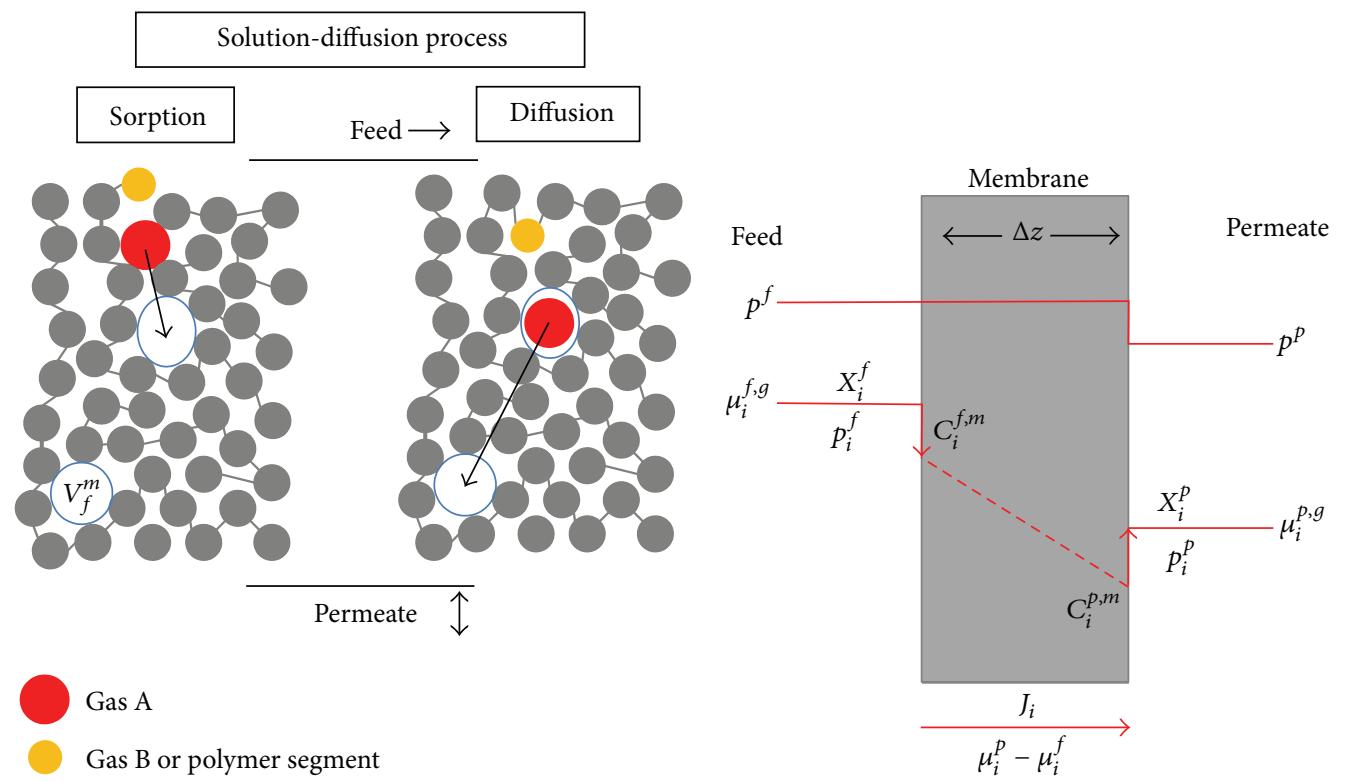

(a)

(b)

FiguRE 2: (a) Schematic representation of the solution-diffusion process of a molecule (A) through a polymer matrix. The diffusion takes place in the free volume $\left(V_{i}^{m}\right)$. To avoid reverse diffusion, the free position has to be occupied by another molecule or a polymer segment (B). (b) The transport through a solution-diffusion membrane consists of three relevant steps: sorption, diffusion, and desorption ( $\mu$ designates the chemical potential, $X$ is the mole fraction, $C$ is the concentration, $p$ is the partial pressure, $J$ is the flux, $z$ is the layer thickness, the subscript $i$ indicates a material component, and the superscripts $f, p, g$, and $m$ indicate the material component in the feed $(f)$, the material component in the permeate $(P)$, the physical state (gaseous: $g$ ), and the membrane matrix $(m)$ ).

and the activities in feed and permeates. This is shown schematically in Figure 2.

The mass transfer through a dense polymer membrane has three important steps. In the first step, a sorption of various molecules according to the distribution coefficients of the feed phase takes place. The second step is the diffusion through the membrane matrix. The difference between the chemical potentials $\mu_{i}^{p}-\mu_{i}^{f}$ is always greater for a retained component than for a permeating component. The rate of diffusion of individual components of a substance mixture through a dense membrane is primarily determined by the respective product of solubility and mobility rather than by the driving forces. The ratio is thus also a measure for the selectivity. In the last step desorption of the components into the permeate phase takes place.

The general form of the transport equation for the solution-diffusion model is

$$
J_{i}=-C_{i}^{m} \cdot b_{i}^{m} \cdot \frac{d \mu_{i}^{m}}{d z}
$$

A relationship between the mobility $b_{i}^{m}$ and the thermodynamic diffusion coefficient $D_{i}^{m}$ is provided by the NernstEinstein equation
Here $R$ denotes the universal gas constant and $T$ is the temperature. This can be further expanded to the diffusion equation

$$
J_{i}=-C_{i}^{m} \cdot \frac{D_{i}^{m}}{R \cdot T} \cdot \frac{d \mu_{i}^{m}}{d z}=-L_{i} \cdot \frac{d \mu_{i}^{m}}{d z} .
$$

Here $J_{i}$ is the flux, $L_{i}$ is a phenomenological constant, $\mu$ is the chemical potential, and $z$ denotes the direction perpendicular to the membrane surface. The superscript $m$ refers to the membrane and the subscript $i$ to a substance component. Assuming that there is a chemical equilibrium at the phase boundaries between the membrane surface and feed or permeate phase, the change in the chemical potential of a material component is provided as a function of pressure at constant temperature:

$$
\frac{d \mu_{i}}{d z}=\frac{1}{d z} \cdot\left(V_{i} d p+R T d \ln a_{i}\right),
$$

where $a$ is the activity, $p$ is the pressure, and $V$ is the partial molar volume. Thus the following relationship for the flux $J_{i}$ can be derived:

$$
J_{i}=-L_{i} \frac{1}{d z}\left(R T d \ln a_{i}^{m}+V_{i} d p\right) .
$$


Assuming further that the pressure inside the membrane is constant $(d p=0)$, the second term is omitted and the flux is given by

$$
J_{i}=-L_{i} R T \frac{d \ln a_{i}^{m}}{d z}=\frac{L_{i} R T}{a_{i}^{m}} \cdot \frac{d a_{i}^{m}}{d z} .
$$

The integration of (7) gives the flux as a function of the activity of a substance component $i$ between the feed and permeate phase:

$$
J_{i}=-L_{i} \frac{R T}{\bar{a}_{i}^{m}} \cdot \frac{a_{i}^{m p}-a_{i}^{m f}}{\Delta z},
$$

where $\bar{a}_{i}^{m}$ is the average activity and $\Delta z$ is the layer thickness of the membrane. The superscripts $m, f$, and $p$ refer to the phase boundary between the membrane surface and the adjacent feed and permeate phase. A correlation of the phase boundary to the gas phase $(g)$ is given by

$$
a_{i}^{m f}=\frac{a_{i}^{g f} \cdot p^{f}}{p_{i}^{0}}, \quad a_{i}^{m p}=\frac{a_{i}^{g p} \cdot p^{p}}{p_{i}^{0}} .
$$

Therein $p$ denotes the vapor pressure and $p_{0}$ the saturation vapor pressure of a substance component $(i)$. The superscripts $f$ and $p$ refer to the feed and permeate. Substituting the two correlations in (8) we obtain for the flux $\left(J_{i}\right)$ the following expression:

$$
J_{i}=-L_{i} \frac{R T}{\bar{a}_{i}^{m} \cdot p_{i}^{0}} \cdot \frac{a_{i}^{g p} \cdot p^{p}-a_{i}^{g f} \cdot p^{f}}{\Delta z} .
$$

With the definition of concentration $\left(C_{i}^{m}\right)$ of a substance component $i$ in the membrane, the relationship between the phenomenological coefficient $\left(L_{i}\right)$ and the diffusion coefficient $\left(D_{i}^{m}\right)$ is

$$
C_{i}^{m}=\frac{\rho_{i}^{m}}{M_{i}} \cdot \frac{\varphi_{i} \cdot p_{i}}{\gamma_{i} \cdot p_{i}^{0}}=\frac{\rho_{i}^{m}}{M_{i}} \cdot X_{i}^{m}, \quad L_{i}=\frac{D_{i}^{m} \cdot C_{i}^{m}}{R T} .
$$

With the assumption that the fugacity coefficients in permeate and feed are the same $\left(\varphi_{i}^{p}=\varphi_{i}^{F}\right)$, we obtain from (10)

$$
\begin{aligned}
J_{i} & =-D_{i}^{m} \cdot \frac{\varphi_{i} \cdot \rho_{i}^{m}}{\bar{\gamma}_{i} \cdot p_{i}^{0} \cdot M_{i}} \cdot\left(\frac{p_{i}^{p}-p_{i}^{f}}{\Delta z}\right) \\
& =-D_{i}^{m} \cdot k_{i} \cdot\left(\frac{p_{i}^{p}-p_{i}^{f}}{\Delta z}\right),
\end{aligned}
$$

where $D_{i}$ is the coefficient of diffusion, $\varphi_{i}$ the fugacity coefficient, $\rho_{i}$ the density, $\bar{\gamma}_{i}$ the average activity coefficient, $p$ the pressure, $M$ the molecular weight, $\Delta z$ the thickness of the membrane, and $k_{i}$ the sorption coefficient. The superscripts $p, f, m$, and 0 refer to permeate and feed, the membrane, and a state of equilibrium. The product of diffusion and sorption coefficients is called the permeability coefficient $\left(P_{i}\right)$ :

$$
P_{i}=D_{i} \cdot k_{i}
$$

The two coefficients for the diffusion $\left(D_{i}\right)$ and sorption $\left(k_{i}\right)$ represent the most important parameters describing the release properties of dense polymer membranes. The diffusion coefficient depends on the membrane structure (mutual disposition and dynamics of polymer segments), the size of the permeating substance components, and the temperature. With the proviso that no phase transitions in the polymer matrix or in the penetrant take place (such as glass transition point or boiling point) and the permeate pressure is less than the saturation vapor pressure, the temperature dependence of the diffusion coefficient can be described by a Van't Hoff Arrhenius relationship:

$$
D_{i}=D_{0} \exp \left(\frac{E_{D}}{R T}\right)
$$

Here $D_{i}$ denotes the diffusion coefficient and $D_{0}$ a preexponential factor and $E_{D}$ is the activation energy needed to create and reach a void in the polymer matrix. Meares [71] proposed the following relation for the activation energy of diffusion:

$$
E_{D}=0.25 \cdot N_{0} \cdot \pi \cdot d^{2} \cdot \lambda \cdot \operatorname{CED} \text { mit } \operatorname{CED}=\frac{E_{\mathrm{coh}}}{V_{m}}
$$

$N_{0}$ is the Avogadro constant, $d$ the kinetic diameter, $\lambda$ the horizontal separation, CED the cohesive energy density, $E_{\text {coh }}$ the cohesive energy, and $V_{m}$ the specific volume of the polymer. The preexponential factor $D_{0}$ in (14) can be described for dense polymers in a first approximation using the Einstein-Smoluchowski relationship:

$$
D_{0}=\frac{\lambda \cdot v_{\mathrm{th}}}{2}
$$

Here $\lambda$ denotes the distance that it takes a diffusing component to reach the nearest empty space from a position of equilibrium and $v$ is its mean thermal velocity. From the relations in (14) it is clear that the diffusion coefficient increases with increasing temperature. The relationships (15) and (16) illustrate the dependence of the diffusion coefficient on the molecular size and the voids in the polymer. The diffusion coefficient decreases with increasing molecular size or increasing molecular weight. So in glassy polymers higher activation energy is required to form an empty space as in elastomeric polymers. For this reason, the diffusion coefficient is higher in the rubbery polymer and decreases in smaller steps with increasing molecular weight. Furthermore, because of their small molecular weight, small molecules need lower activation energy to reach the nearest empty space than larger molecules. This explains why preferably small molecules are transported in dense glassy polymers.

The diffusion of small molecules in the gas or vapor phase correlates with the fractional free volume (FFV) in the polymer matrix. This relationship is valid for material components with no or only a weak interaction with the polymer chains (e.g., $\mathrm{He}, \mathrm{N}_{2}, \mathrm{H}_{2}$, and $\mathrm{CO}_{2}$ ). The $\mathrm{FFV}$ 
model is an empirical model which postulates an exponential relationship between the diffusion coefficient and the FFV:

$$
\begin{aligned}
D_{i} & =A_{i} \exp \left(\frac{B_{i}}{\mathrm{FFV}}\right) \text { mit FFV }=\frac{V_{m}-V_{i, o}}{V_{m}} \\
& =\frac{V_{m}-1.3 \cdot V_{W}}{V_{m}} .
\end{aligned}
$$

$A_{i}$ and $B_{i}$ are therein adjustable parameters that correlate with the diameter, volume, and shape of the material components. These parameters are not yet clearly defined, because different units of measurement are used to describe the diameter and volume, such as the kinetic, Lennard-Jones, and Chung diameter, and the critical volume and the van der Waals volume exist. Both the cross-sectional area and the length of the molecules affect the diffusion through polymeric membranes. The FFV of a polymer is described by its specific volume $V_{m}$ (reciprocal density of the polymer), by a constitutional repeating unit per mole at $0 \mathrm{~K}$ occupied volume $V_{i, 0}$ and the van der Waals volume of $V_{W}$. The FFV is thus the sum of the voids between the polymer chains. A good correlation between the diffusion coefficient and the FFV is only observed with structurally related polymers, limiting the application of this model. The distribution and size of voids in thick nonconductive polymer can be determined, for example, using Positron Annihilation Lifetime Spectroscopy (PALS) $[72,73]$. As it was already mentioned, this model does not take into account any interactions between the gas molecules and the polymer chains. There is a correlation between the dielectric constant $\varepsilon$ of polymer membranes and the FFV. A connection with the diffusion coefficient is given in the Clausius-Mossotti equation:

$$
D_{i}=A_{i}^{*} \exp \left(\frac{-B_{i}^{*}}{1-a}\right) \text { mit } a=1.3 \cdot \frac{V_{W}}{P_{L L}} \cdot \frac{\varepsilon-1}{\varepsilon+2} .
$$

Here $A_{i}^{*}$ and $B_{i}^{*}$ are adjustable parameters, $V_{W}$ the specific van der Waals volume, and $P_{L L}$ the molar polarization. The additional consideration of the electrical interaction leads to an improved correlation of the diffusion coefficient with structurally related polymers.

The second important parameter to describe the permeability and the release properties of dense polymer membranes is the sorption coefficient. The sorption coefficient $k_{i}$ can be calculated using (11) and (12):

$$
k_{i}=\frac{\varphi_{i} \cdot \rho_{i}^{m}}{\bar{\gamma}_{i} \cdot p_{i}^{0} \cdot M_{i}}=\frac{C_{i}^{m}}{p_{i}},
$$

where $\varphi_{i}$ is the fugacity coefficient, $\rho_{i}$ the density, $\bar{\gamma}_{i}$ the mean activity coefficient, $p^{0}$ the saturation pressure, and $M$ the molecular weight. The temperature dependence of the sorption coefficients can be described just as for the diffusion coefficient using the Van't Hoff Arrhenius relationship:

$$
\begin{array}{r}
k_{i}=k_{0} \exp \left(-\frac{\Delta H_{S}}{R T}\right) \text { mit } \Delta H_{S}=\Delta H_{m}+\Delta H_{c}, \\
\Delta G_{m}=\Delta H_{m}-T \Delta S_{m} .
\end{array}
$$

Here $k_{i}$ is the sorption coefficient of a material component in a polymer, $k_{0}$ is a preexponential factor, $\Delta H_{S}$ is the adsorption heat or adsorption enthalpy, $\Delta H_{m}$ is the enthalpy of mixing, $\Delta H_{c}$ is the enthalpy of condensation, $\Delta G_{m}$ is the free energy of mixing, and $\Delta S_{m}$ is the entropy of mixing. Substances are mutually soluble when the free energy of mixing is negative. The entropy of mixing is usually positive. Therefore, the solubility depends on the value of the adsorption enthalpy $\Delta H_{m}$. The interaction of a dissolved component in a polymer membrane may be described as follows:

$$
\Delta H_{m}=H_{f l}+H_{\mathrm{Pol}}-2 \cdot H_{f l-\mathrm{Pol}} \cdot
$$

Here $H_{f l}$ is the enthalpy of the dissolved component, $H_{\mathrm{Pol}}$ the enthalpy of the polymer material, and $H_{f l \text {-Pol }}$ the enthalpy between the dissolved component and the polymer. A correlation to the solubility parameters is given by

$$
\begin{aligned}
\Delta H_{m} & =V \cdot\left(\delta_{f l}-\delta_{\mathrm{Pol}}\right)^{2} \cdot \phi_{f l} \cdot \phi_{\mathrm{Pol}} \operatorname{mit} \delta \\
& =\left(\frac{E_{\mathrm{coh}}}{V}\right)^{1 / 2},
\end{aligned}
$$

where $V$ is the total molar volume of solute and polymer solubility, $\delta$ are solubility parameters, $\phi$ is the volume fraction, and $E_{\text {coh }}$ is the cohesive energy. In endothermic mixtures the adsorption enthalpy is always positive. To obtain a negative free energy of mixing, $\Delta H_{m}<T \Delta S_{m}$ must be true and thus the difference in the solubility parameters between material component and polymer must be minimal. If $\delta_{f l} \approx \delta_{\mathrm{Pol}}$, $\Delta H_{m}$ goes to zero and the material component is soluble in the polymer material. In case the solubility parameters of the material component and the polymer membrane are greatly different, the solid component is retained by the membrane. The retention capacity $R_{i}$ of a polymer membrane is defined as

$$
R_{i}=\left(1-\frac{C_{i}^{p}}{C_{i}^{f}}\right)
$$

$C$ denotes the concentration of a substance component $i$ in the permeate $(p)$ and the feed $(f)$. The dimensionless term varies between zero (no permeability) and 1 which is equal to a total permeability of a material component $i$. A relationship between the equilibrium concentration $C_{i}^{m}$ of a component in the polymer phase and the sorption coefficient is given according to Henry's law by

$$
C_{i}^{m}=k_{i} \cdot p_{i}=K_{i}^{H} \cdot p_{i} .
$$

For ideal gases the sorption coefficient $k_{i}$ is constant and corresponds to the Henry constant $K_{i}^{H}$ of a component $i$. This linear assumption applies only to small concentrations and is observed only in rubber-elastic polymers. Upon interaction of a penetrant and polymer matrix, a swelling can occur in rubbery polymers or polymers close to the glass transition point $\left(T_{g}\right)$, due to which the solubility increases. When 
polymers are close to $T_{g}$, we call it plastification. The solubility isotherm then shows a progressive deviation from the linear behavior and is described by the Flory-Huggins polymer theory. In glassy polymer membranes, the solubility isotherm however shows a degressive behavior upon increasing partial pressure. This behavior is described by the dual sorption model, which includes, in addition to the linear Henry sorption, surface adsorption according to the Langmuir relationship:

$$
C_{i}=C_{i}^{H}+C_{i}^{L}=K_{i}^{H} \cdot p_{i}+\frac{C_{i}^{L^{\prime}} b p_{i}}{1+b p_{i}} .
$$

Here $C_{i}^{H}$ is the Henry sorption, $C_{i}^{L}$ the Langmuir sorption, $K_{i}^{H}$ the Henry constant, $p_{i}$ the partial pressure, $C_{i}^{L^{\prime}}$ the "hole saturation" constant, and $b$ the so-called hole-affinity constant. The solubility of many permanent gases in glassy polymers is described quite well by the dual sorption model. Another important parameter to describe the separation properties of dense polymer membranes is their selectivity:

$$
S_{j, k}^{P}=\frac{P_{j}}{P_{k}}=S_{j, k}^{D} \cdot S_{j, k}^{k} .
$$

The selectivity $S_{j, k}^{p}$ is the ratio of the permeability of a material component $j$ to a substance component $k$, if the material component $j$ is having the higher permeability through the membrane structure. The selectivity is sometimes split into two terms. The first term is the ratio of the diffusion coefficients $(D)$ and the second term the ratio of the sorption coefficients $(k)$ of the material components $j$ and $k$. The permselectivity (separation factor) is another useful parameter for describing binary mixtures:

$$
\alpha_{j, k}=\frac{X_{j}^{p}}{X_{j}^{f}} \frac{X_{k}^{f}}{X_{k}^{p}}=\frac{X_{j}^{p} \cdot\left(1-X_{j}^{f}\right)}{X_{j}^{f} \cdot\left(1-X_{j}^{p}\right)} .
$$

Here $X$ is the mole fraction of a material component $j$ and $k$ in the permeate $(p)$ and the feed $(f)$. The separation factor is by definition always $>1$. A relationship to the selectivity is given by

$$
\alpha_{j, k}=S_{j, k} \frac{\left(\left(X_{j}^{p} \cdot p^{p}\right) / p^{f}-X_{j}^{f}\right)}{\left(\left(X_{k}^{p} \cdot p^{p}\right) / p^{f}-X_{k}^{f}\right)} \frac{X_{k}^{f}}{X_{j}^{f}} .
$$

$S$ refers to the selectivity of a binary mixture, $X$ is the mole fraction, and $p$ is the partial pressure. The superscripts refer to the permeate $(p)$ and the feed $(f)$ and the subscripts to material components $f$ and $k$. The separation factor is always smaller than the selectivity. If the partial pressure in the feed is much larger than in the permeate the separation factor is equal to the selectivity:

$$
\lim _{p^{p} / p^{f} \rightarrow 0} \alpha_{j, k}=S_{j, k}
$$

This can be concluded as follows: the flux through a nonporous dense membrane depends on the diffusion and sorption of a material component. The product of diffusion and sorption coefficients is called the permeability coefficient $\left(P_{i}\right)$. The diffusion coefficient $D_{i}$ correlates with the molecular diameter of the material components and increases with increasing molecular diameters. The decrease is in glassy polymers $\left(T<T_{g}\right)$ more pronounced than in the rubber-elastic polymers $\left(T>T_{g}\right)$. The diffusion coefficient increases with temperature, as with the temperature also the fractional free volume (FFV) increases in the polymer. The sorption coefficient $k_{i}$ of gases or vapors rises with the boiling point and the critical temperature of the adsorbed material components. For gases above the critical temperature, the adsorption enthalpy $\Delta H_{s}$ is slightly positive and is typically between 0 and $10 \mathrm{kJmol}^{-1}$. Therefore, the solubility increases only moderately with temperature. For condensable gases $\Delta H_{s}$ is due to the high contribution of the condensation enthalpy $\Delta H_{c}$ negative (see (20)) and the solubility decreases with increasing temperature. Sorption in glassy polymers thereby differs only slightly from elastomeric polymers. The dependence of the permeability coefficient $P_{i}$ from the molecular diameter is comparatively low in rubbery polymers and increases only slightly with increasing diameter of the molecules. In glassy polymers, the permeability coefficient generally decreases with increasing molecular diameter. In permanent gases the permeability increases with temperature. This can be explained in the way that the diffusion depends a lot more on the temperature (activation energy for diffusion is between 20 and $80 \mathrm{kJmol}^{-1}$ ) than on the sorption (adsorption enthalpy is usually between -10 and $\left.+10 \mathrm{kJmol}^{-1}\right)$. In vapor molecules, the condensation enthalpy $\Delta H_{c}$ is the dominating term. For this reason, the permeability decreases for molecules in the vapor state with increasing temperature $[9,56,74-76]$. Important parameters to describe the release characteristics of the polymer are thus the permeability just described $(P)$ and the retention capacity $(R)$. When considering binary mixtures often the selectivity $(S)$ or the separation factor $(\alpha)$ for the characterization of membranes are used.

2.3. MOX Sensor. A MOX sensor changes its electrical resistance in contact with gases. The operating principle of MOX sensors is based on the chemisorption of gases in the presence of atmospheric oxygen. The presence of reducing and oxidizing gases leads to a change of the induced depletion layer at the outer edge of the metal oxide grains and thus to a change in the sensor resistance. In all our experiments we used a tin oxide sensor with palladium catalyst $\left(\mathrm{SnO}_{2}: \mathrm{Pd}\right)$, which is an $n$-type semiconductor. Upon exposure to reducing gases such as $\mathrm{H}_{2}, \mathrm{CO}, \mathrm{CH}_{4}$, ethanol, acetone, and acetaldehyde, excess electrons are emitted into the conduction band of the $\mathrm{SnO}_{2}$. This results in an increase of the carrier concentration on the $\mathrm{SnO}_{2}$ surface and the resistance of the sensor is reduced. Oxidizing gases such as $\mathrm{NO}_{2}$ reduce the charge carrier concentration, the Schottky barrier is increased and the resistance of the sensor increases. The sensor signal $(S)$ is used as relation between the signal at 
equilibrium $\left(x_{0}\right)$ and the signal in a changing gas composition $(x)$ :

$$
\begin{aligned}
S & =\frac{x}{x_{0}} \longrightarrow S_{\text {red }}=\frac{R_{\text {air }}}{R_{\text {gas }}} \geq 1 ; \\
S_{\text {ox }} & =\frac{R_{\text {gas }}}{R_{\text {air }}} \geq 1 .
\end{aligned}
$$

$R_{\text {air }}$ denotes the resistance of the sensor in pure synthetic air (baseline) and upon reaction with gas changing the resistance to $R_{\mathrm{gas}}$. In order to obtain positive values, the relation of the sensor signal $\left(S_{\text {red }}, S_{\text {ox }}\right)$ must be reciprocal for reducing and oxidizing gases. The sensor signal is always $\geq 1$. If the signal is $\cong 1$ no change in resistance takes place. The sensor signal now corresponds per definition to the permeability $(P)$.

In addition to the permeability, the retention capacity is another important parameter to describe the separation properties of polymers. The retention capacity $(R)$ is defined as the normalized ratio of the concentration of a solid component $(i)$ in the permeate $(p)$ to the concentration in the feed $(f)$. The sensor signals are proportional to the true concentration. This requires an adaptation of (23):

$$
\begin{aligned}
\bar{R}_{i} & =\left(1-\frac{c_{i}^{p}}{c_{i}^{f}}\right)=\underbrace{\left(1-\frac{S_{i}^{p}-1}{S_{i}^{f}-1}\right)}_{\text {MOS }} ; \\
\operatorname{mit} \bar{R}_{i} & =\frac{1}{3} \sum_{i=1}^{3} R_{i},
\end{aligned}
$$

where $c$ is the concentration, $S$ is the sensor signal of MOX sensors from (30), the subscript $i$ refers to a material component, and the superscript $p$ or $f$ refers to the permeate and feed. Since the $\mathrm{SnO}_{2}: \mathrm{Pd}$ sensors have a high reproducibility between 89 and 94, two different sensors can be used to measure the concentration in the feed and permeate. The reproducibility $(Q)$ is defined as

$$
Q_{x^{\prime}}\left(p_{i}^{\prime}\right)=\left(\left.\frac{(1 / n) \sum_{k=1}^{n} x_{k}^{\prime}}{x_{\max }^{\prime}}\right|^{p_{i}}\right) \cdot 100,
$$

where $n$ is number of sensors, $x_{k}^{\prime}$ is signal of sensor $k$, and $x_{\max }^{\prime}$ is signal maximum of all sensors.

In the case of $Q=0$, the sensors are mutually not reproducible; in the case of $Q \approx 100$, the signals are identical [77].

If now the retention capacity reaches a value of 1 , the membrane is completely permeable for a material component. If the retention capacity is zero, then a material component can diffuse freely through the membrane.

\section{Experimental Setup}

As mentioned in the introduction, for many application fields of gas sensors, there is a great interest in membranes with high selectivity and permeability, having at the same time the smallest possible diameter. Typically, gas sensors are mounted on TO-39 sockets. The metal or plastic caps that are glued onto the socket to protect the sensors usually have an outer diameter of about $8 \mathrm{~mm}$. For easy integration, the diameter of the membranes must not exceed $6.4 \mathrm{~mm}$. The membranes we used are symmetrical dense polymer membranes without support layer with thicknesses between $8 \mu \mathrm{m}$ (PI) and $50 \mu \mathrm{m}$ (PMP). In order to prevent damage or deformation of the thin membrane during installation, they are fixed on polymer supports. This is shown schematically in Figure 3(a). A stainless steel plate (A) with an outer diameter of $12 \mathrm{~mm}$ and a height of $1.6 \mathrm{~mm}$ is the basis for applying a nonoutgassing, two-component epoxy adhesive at the edge (H70E-4 Company EPO TEK Inc.) (B). The inner diameter of the stainless steel plate is $6.4 \mathrm{~mm}$.

The membrane is punched out, placed on the stainless steel plate, and lightly pressed with a pair of tweezers, so that the adhesive runs under the membrane. Then another layer of glue is applied at the edge (C). In the last step, a second stainless steel plate is placed on top and pressed on and afterwards the adhesive cured for two hours at a temperature of $80^{\circ} \mathrm{C}(\mathrm{D})$. The stainless steel plate directed towards the membrane side is trimmed and polished. The photo on the right shows an assembled carrier with membranes of polytetrafluoroethylene (PTFE), polyetheretherketone (PEEK), and polyimide (PI).

The experimental setup consists of two chambers connected in series. The chambers are interconnected by means of Swagelok. Chamber A is made of Teflon (PTFE). The chamber is used to measure the concentration, humidity, and temperature in the feed. The chamber can be equipped with up to six sensors mounted on TO-39 sockets. The sensors comprise $\mathrm{MOX}$ gas sensors $\left(\mathrm{SnO}_{2}: \mathrm{Pd}\right)$, and temperature and humidity sensors (HYT221) from IST AG, Switzerland. A metal cap is glued onto a printed circuit board (PCB), which is just the same as the caps on the HYT221 and the gas sensors. The housing of the sensor is integrated into the PTFE chamber. Chamber B is used to measure the concentration of the permeate. Six stainless steel fittings from Serto (SO 51194$8-1 / 4)$ with an inner diameter of $8 \mathrm{~mm}$ are screwed into the measuring chamber made of aluminum. The tightness of the setup is crucial for the examination of the membranes. For this purpose, the TO-39 sockets with the gas sensors (not the HYT221) are soldered to the fitting. The membrane supports are interchangeable and can be screwed to the fitting. The volume of gas below the diaphragm is $1.51 \mathrm{~cm}^{3}$. The tightness of the part at the membrane is ensured by the use of two PTFE sealing disks above and below the carrier, as well as a further ethylene propylene diene monomer (EPDM) rubber sealing ring. The thread is additionally sealed with PTFE tape. The schematic structure is illustrated in Figure 4.

The tightness of the structure (polymeric carrier, stainless steel fittings, seals, etc.) was examined by carriers that have been built with $100 \mu \mathrm{m}$ thick gas-tight aluminum foil. In a test, $1,000 \mathrm{ppm} \mathrm{H}_{2}$ was applied over a period of 20 minutes. The $\mathrm{SnO}_{2}: \mathrm{Pd}$ sensors would show already at a very low concentration of $1 \mathrm{ppm} \mathrm{H}_{2}$ sensor signals in the order of 7, so that even smallest leaks in the system could be noticed. In the test, no leak was observed. 


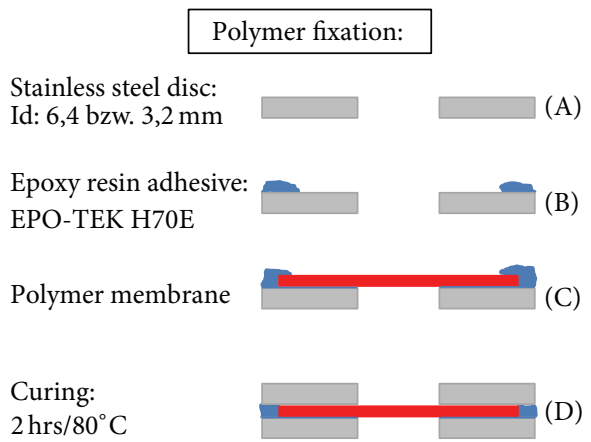

(a)

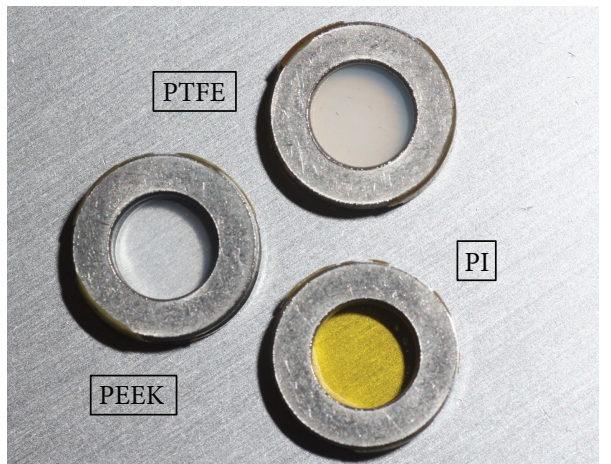

(b)

Figure 3: (a) Construction of polymer support: (A) stainless steel plates with an inner diameter of $6.4 \mathrm{~mm}$, an outer diameter of $12 \mathrm{~mm}$, and a height of $1.6 \mathrm{~mm}$ are used as substrates; (B) addition of a two-component epoxy adhesive (EPO-TEK H70E Company Epoxy Technology Inc.); (C) placing of the polymer membrane; (D) pressing of a second stainless steel plate and curing of the adhesive for two hours at $80^{\circ} \mathrm{C}$. (b) Photo of polymeric carriers with membranes of PI, PTFE, and PEEK.

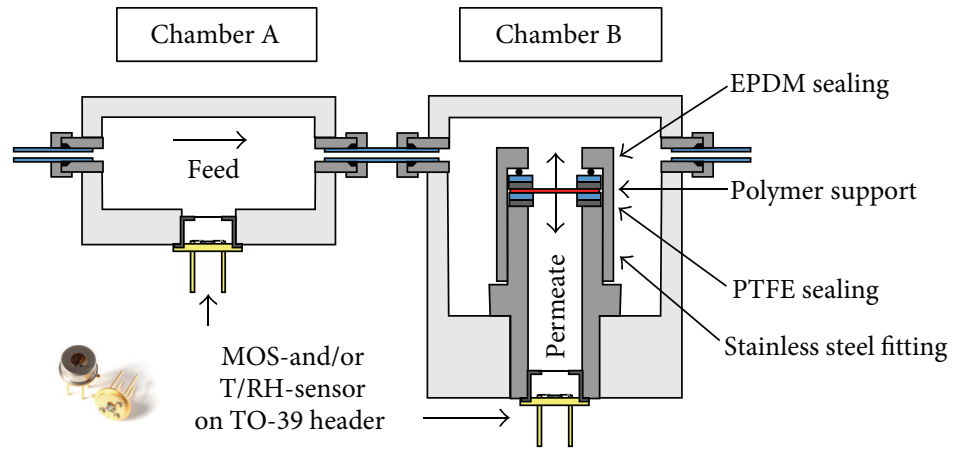

FIGURE 4: Experimental setup for investigating the separation properties of polymer membranes. In chamber A, any six sensors that are mounted on TO-39 sockets can be integrated. The sensors are used to measure the gas concentration, humidity, and temperature in the feed. In chamber B six interchangeable stainless steel fittings are integrated. The sensors are soldered into the fitting. The polymer supports are screwed with EPDM and PTFE seals into the fitting.

In a second test, the sensor signals of $\mathrm{SnO}_{2}: \mathrm{Pd}$ sensors in chamber A were compared with those of chamber $\mathrm{B}$ (without polymer carrier) during 20-minute exposure to $\mathrm{H}_{2}(150 \mathrm{ppm}), \mathrm{CO}(30 \mathrm{ppm}), \mathrm{CH}_{4}(1,000 \mathrm{ppm})$, ethanol $(500 \mathrm{ppm})$, acetone $(500 \mathrm{ppm})$, and acetaldehyde $(25 \mathrm{ppm})$, and additionally to different humidity levels. The sensor signals in chamber A and chamber B show a very good agreement and can therefore be used to calculate the retention capacity.

\section{Results}

4.1. Polyolefins. From the group of polyolefins, the semicrystalline homopolymers of polyethylene with high density (HDPE), low density (LDPE), graphite filling ( $\mathrm{PE}+$ graphite), polypropylene (PP), and poly-4-methylpentene-1 (PMP) were tested for their separation properties. In Figure 5, the feed and permeate signals upon exposure to $150 \mathrm{ppm} \mathrm{H}_{2}$, $30 \mathrm{ppm} \mathrm{CO}, 1,000 \mathrm{ppm} \mathrm{CH}_{4}, 500 \mathrm{ppm}$ ethanol, $500 \mathrm{ppm}$ acetone, and $25 \mathrm{ppm}$ acetaldehyde are shown. For illustration, the cross-links in HDPE and LDPE are also shown schematically.

For the LDPE membrane, we obtained high signal changes for $\mathrm{H}_{2}$, ethanol, and acetone, and small signal changes for $\mathrm{CH}_{4}$ and acetaldehyde. Only CO was completely retained by the LDPE membrane. In the HDPE membrane, $70-80 \%$ of the macromolecules are in orthorhombic crystalline form, that is, in a highly ordered state with the greatest packing density (crystal lamellae). In this condition, the intermolecular partial valence forces act optimally. Interestingly, this leads to increased permeability for $\mathrm{H}_{2}$, ethanol, acetone, acetaldehyde, and $\mathrm{CH}_{4}$. This can be explained with the fact that, due to a decrease in entanglement (amorphous regions) compared to LDPE, the mobility of the chains and thus the diffusion is facilitated by the membrane matrix. The graphite filling in $\mathrm{PE}+$ graphite causes an increase in the density and thus a reduction of the free volume. This increases the retention capacity and the membrane is permeable only to the gases acetone and ethanol. 
TABLE 2: Permeate signals of the MOX sensor using LDPE, HDPE, PE + graphite, PP, and PMP membranes. The values given are the arithmetic mean of three measurements.

\begin{tabular}{|c|c|c|c|c|c|c|c|}
\hline Membrane & Sensor & $\mathrm{H}_{2}$ & $\mathrm{CO}$ & $\mathrm{CH}_{4}$ & Ethanol & Acetone & Acetald. \\
\hline LDPE & MOX & 2,1 & - & - & 32,5 & 21,9 & - \\
\hline HDPE & MOX & 2,7 & - & - & 80,9 & 70,9 & 1,3 \\
\hline $\mathrm{PE}+$ graphite & MOX & - & - & - & 1,5 & 1,7 & - \\
\hline PP & MOX & 2,3 & - & - & 4,4 & 3,2 & - \\
\hline PMP & MOX & 5,8 & - & 1,1 & 29,6 & 13,2 & 1,1 \\
\hline
\end{tabular}

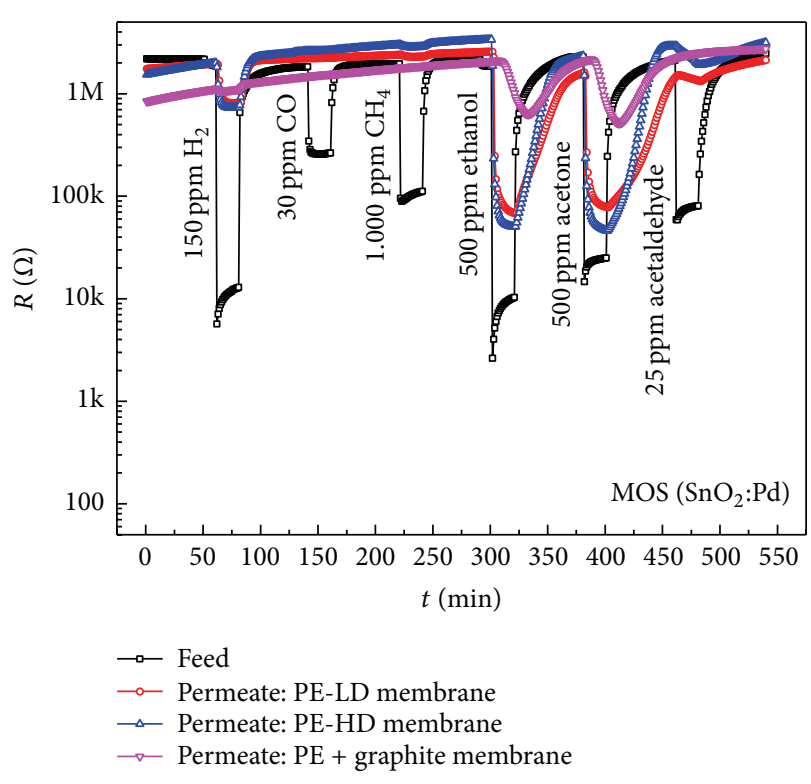

(a)

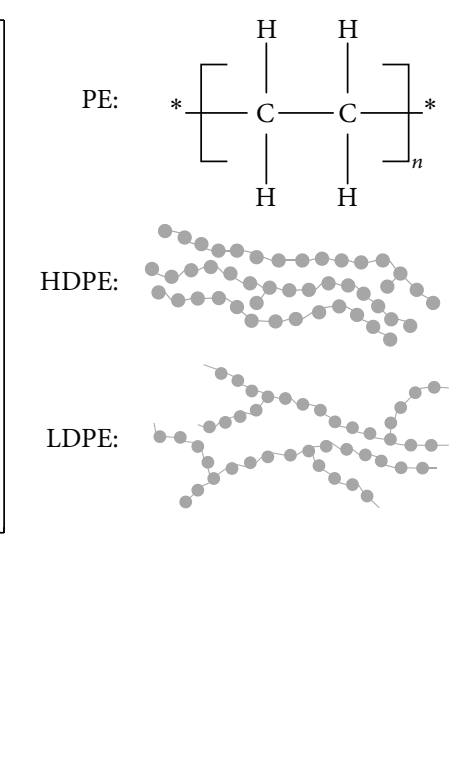

(b)

FIGURE 5: (a) Separation properties of LDPE, HDPE, and PE + graphite upon exposure to $150 \mathrm{ppm}_{2}, 30 \mathrm{ppm} \mathrm{CO}, 1,000 \mathrm{ppm} \mathrm{CH}_{4}, 500 \mathrm{ppm}$ ethanol, $500 \mathrm{ppm}$ acetone, and $25 \mathrm{ppm}$ acetaldehyde. The diameter of the membranes is $6.4 \mathrm{~mm}$. (b) structure of the PE monomer and crosslinking of the macromolecules in HDPE and LDPE.

The MOX signals using the HDPE, PP, and PMP membranes are shown in Figure 6. For the PP membrane, the sensor signals are $\sim 20 \mathrm{x}$ lower in comparison with the HDPE membrane when exposed to ethanol and acetone. In contrast, the sensor signal change in response to $\mathrm{H}_{2}$ is only minimal. Due to the methylene side group and the resulting lower density (low density is synonymous with large interatomic distances), one would rather expect an increase in signals.

In contrast to LDPE, in which a decreased sensor signal can be assigned to entanglement in amorphous regions, this cannot be the reason in PP because this has a similar degree of crystallinity compared to HDPE. It can therefore be assumed that the increased retention capacity is associated with the $3_{1}$ helices which PP is forming. The assumption is reinforced by the fact that even when using the PMP membrane lower feed signals are obtained for ethanol and acetone. Due to different linear thermal expansion coefficients, PMP tends to build up cavities between the amorphous and crystalline regions, and the sensor signal increases for hydrogen and is even more pronounced for $\mathrm{CH}_{4}$ and acetaldehyde. The permeate signals of the examined polyolefins are summarized in Table 2.
Involving the feed signals we obtain the results summarized in Table 3 for the retention capacities of the different polymers. If the adjacent gas phase and the polymer are both nonpolar, this should lead to a substantial increase in the adsorption of the adjacent phase and an associated increase in the diffusion. The investigated polyolefins are all nonpolar but exhibit a high permeability for the polar gas ethanol (1.69 Debye) and acetone (2.88 Debye), while the nonpolar methane and the weakly polar CO (0.11 Debye) are completely held back. In the case of the polyolefins, a relatively high retention capacity with respect to the nonpolar $\mathrm{H}_{2}$ is observed. The thermoplastics show both a permeability to nonpolar and polar gases and are therefore little selective, with the exception of HDPE. In the HDPE membrane, the retention capacity is for acetone at 0.305 , which is significantly lower than the retention capacity for ethanol, acetaldehyde, $\mathrm{CO}, \mathrm{H}_{2}$, and methane. Thus it shows an increased selectivity to acetone.

In these nonpolar polyolefins, the macromolecules are held together only by weak dispersion forces. These forces are most pronounced in the highly ordered crystalline domains. 
TABLE 3: Retention capacities of the polyolefins LDPE, HDPE, PE + graphite, PP, and PMP. The values given are the arithmetic mean of three measurements.

\begin{tabular}{lccccccc}
\hline Membrane & Sensor & $\mathrm{H}_{2}$ & $\mathrm{CO}$ & $\mathrm{CH}_{4}$ & Ethanol & Acetone & Acetald. \\
\hline PE-LD & MOX & 0,993 & - & - & 0,852 & 0,796 & 0, \\
PE-HD & MOX & 0,988 & - & - & 0,619 & 0,305 & 0,99 \\
PE + C & MOX & - & - & - & 0,997 & 0,993 \\
PP & MOX & 0,992 & - & - & 0,983 & 0,978 & - \\
PMP & MOX & 0,969 & - & 0,995 & 0,874 & 0,887 \\
\hline
\end{tabular}

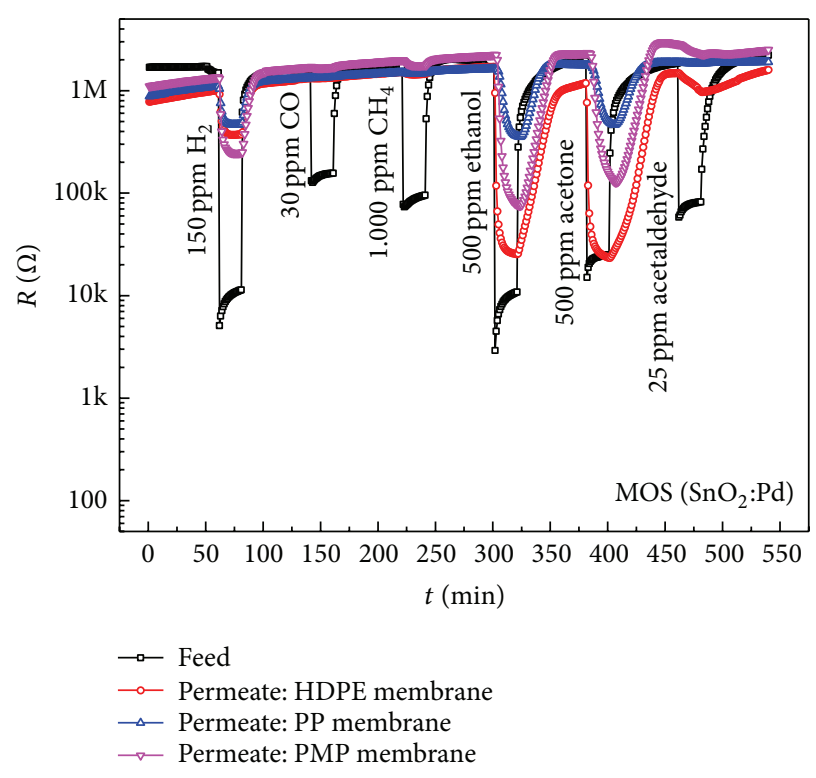

(a)

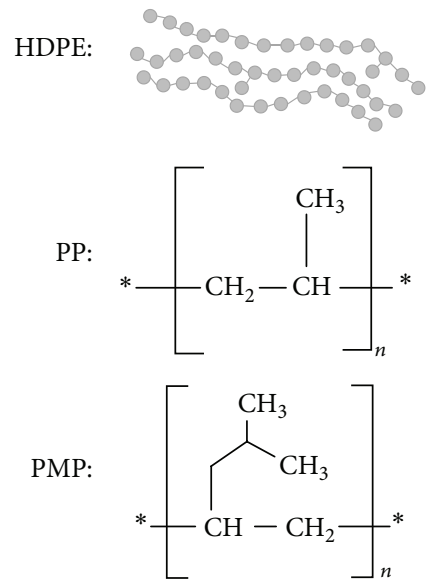

(b)

FIGURE 6: Separation properties of HDPE, PP, and PMP upon exposure to $150 \mathrm{ppm} \mathrm{H}_{2}, 30 \mathrm{ppm} \mathrm{CO}, 1,000 \mathrm{ppm} \mathrm{CH}_{4}, 500 \mathrm{ppm}$ ethanol, $500 \mathrm{ppm}$ acetone, and $25 \mathrm{ppm}$ acetaldehyde. The diameter of the membranes is $6.4 \mathrm{~mm}$.

The degree of crystallization of the membrane increases in the order LDPE $<$ PMP $<$ PP $<$ HDPE. Interestingly HDPE, which consists of largely linear macromolecules having a low degree of branching (i.e., high degree of crystallization), has the lowest retention capacity. Through the introduction of side chains, the interatomic distances between adjacent macromolecules increase. This leads to a decrease in density. The density of the membrane thus decreases in the order of $\mathrm{PE}+$ graphite $>\mathrm{HDPE}>\mathrm{LDPE}>\mathrm{PP}>\mathrm{PMP}$. The measurements have shown that with decreasing density, the retention capacity of the membrane increases, contrary to our expectations. We assume that this effect is related to the chain structure, since the macromolecules in PP and PMP form $3_{1}$ helices, in contrast to the PE types.

We now look at the permeation of water vapor. For this purpose, the absolute humidity was increased in two steps of $4.8 \mathrm{~g} / \mathrm{m}^{3}$ and held for two hours. The concentrations in the feed and permeate is plotted in Figure 7.

The permeability to water vapor is very low in all examined polyolefins (cf. Table 4). So the absolute humidity rises in the permeate during the two-step profile to a maximum of $1.7 \mathrm{~g} / \mathrm{m}^{3}$ in PMP or $1.4 \mathrm{~g} / \mathrm{m}^{3}$ in LDPE.
LDPE is a widely branched homopolymer with shortand long-chain branches and thus has an enlarged molecule distance compared to other PE types (e.g., LDPE or PE + graphite). PMP is a largely isotactic thermoplastic. The bulky side group leads to an abnormally low density of $0.83 \mathrm{~g} / \mathrm{cm}^{3}$. PMP is partially crystalline, with a degree of crystallization of $65 \%$. At room temperature, the amorphous domains are quite dense. Due to the different coefficients of thermal expansion, cavities are forming between the amorphous and crystalline areas. This explains the increased permeability to water vapor in comparison to $\mathrm{PP}, \mathrm{HDPE}$, and $\mathrm{PE}+$ graphite. The water absorption is still less than $0.01 \%$.

4.2. Thermoplastic Polycondensates. The second class of substances, which is analyzed with respect to their separation properties, are thermoplastic polycondensates. Here the membranes are made of polycarbonate (PC), polyether ether ketone (PEEK), polyether sulfone (PES), polyethylene terephthalate $(\mathrm{PET})$, polyethylene naphthalate $(\mathrm{PEN})$, polyamide (PA6), polyimide (PI), and polyetherimide (PEI). Of particular importance in this class of substances are, with the exception of PA6, the aromatic ring compounds, that 
TABLE 4: Changes in the absolute humidity in the permeate when using polyolefin membranes made of LDPE, HDPE, PE + graphite, PP, and PMP. The concentrations in the feed and permeate are measured with a digital T/RH sensor (HYT221).

\begin{tabular}{lccccc}
\hline Membran & Sensor & $\Delta A_{\text {Feed }}\left[\mathrm{g} / \mathrm{m}^{3}\right]$ & $\Delta B_{\text {Feed }}\left[\mathrm{g} / \mathrm{m}^{3}\right]$ & $\Delta A_{\text {Permeat }}\left[\mathrm{g} / \mathrm{m}^{3}\right]$ & 0,7 \\
\hline PE-LD & HYT221 & 4,8 & 9,4 & 0,2 & $\Delta B_{\text {Permeat }}\left[\mathrm{g} / \mathrm{m}^{3}\right]$ \\
PE-HD & HYT221 & 4,9 & 9,6 & 0 & 0,4 \\
PE + C & HYT221 & 5,1 & 10 & 0,2 & 0,2 \\
PP & HYT221 & 4,8 & 9,5 & 0,8 & 0,2 \\
PMP & HYT221 & 4,8 & 9,8 & & 1,7 \\
\hline
\end{tabular}

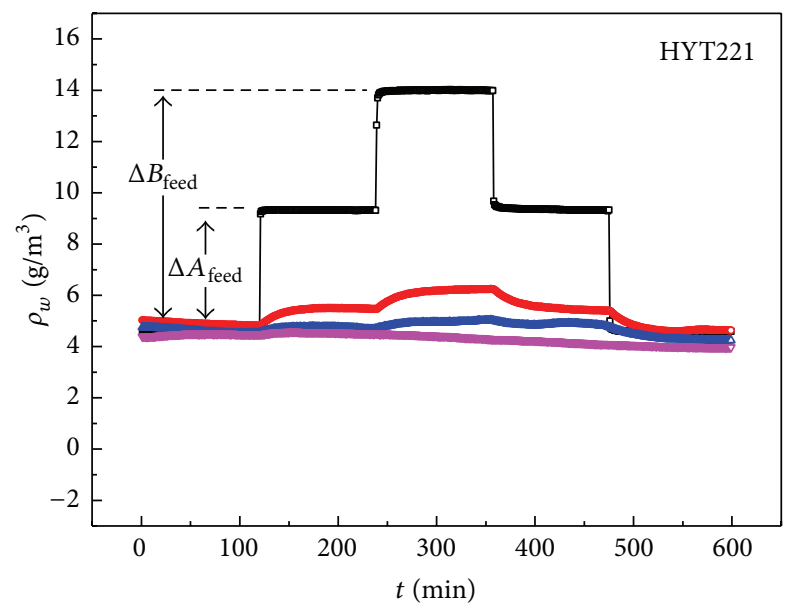

$\rightarrow$ Feed

$\because$ Permeate: PE-LD membrane

$\leadsto$ Permeate: PE-HD membrane

$\rightarrow$ Permeate: PE + graphite membrane

(a)

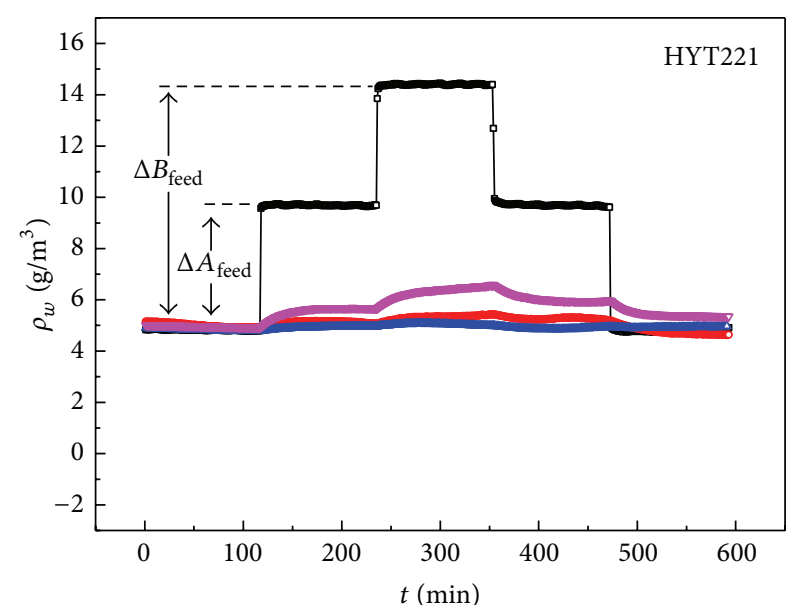

$\multimap-$ Feed
$\multimap-$ Permeate: PE-HD membrane
$\triangleleft-$ Permeate: PP membrane
$\rightarrow-$ Permeate: PMP membrane

(b)

FIGURE 7: (a) Water vapor permeability of LDPE, HDPE, and PE + graphite membranes. (b) Water vapor permeability of the polyolefins HDPE, PP, and PMP. The absolute humidity is increased in two steps of $4.8 \mathrm{~g} / \mathrm{m}^{3}(\Delta A, \Delta B)$.

is, heterocyclic compounds contained in the backbone. In contrast to the flexible and mobile $-\mathrm{CH}_{2}$ groups they lead to a stiffening of the chain links. A linear combination of aromatics via an ether (-O-), ketone (-CO-), sulfone $\left(-\mathrm{SO}_{2}-\right)$, aryl-, or ether imide group leads to a strong increase of both chemical resistance and temperature resistance. The linking of the aromatics via an ester (-CO-O-) or a carbonate group (-O-CO-O-), however, leads to a decrease of the temperature resistance. The continuous operating temperatures are still above those of the polyolefins. In contrast to the already investigated polymers from the class of polyolefins, these polymers should have a lower permeability due to their higher strength and stiffness. This should also lead to a higher selectivity. The majority of the selected polymers are also amorphous (PC, PEEK, PEN, PI, PEI, and PES). In contrast, the polyolefins have degrees of crystallization in the range between $20 \%$ and $80 \%$. In the examined polyolefins the monomers consist exclusively of carbon (C) and hydrogen $(\mathrm{H})$. The investigation of the separation properties of these membranes has shown a high retention capacity compared to nonpolar gases and water vapor. We therefore suppose that by a slight polarization of the polymer, for example, via the inductive effect of an ether group (-O-), the selectivity can be increased to nonpolar gases. The polymers PEEK, PES, PET, PEN, PI, and PEI contain these ether groups in the backbone. Through further linkages of aromatics with ketone (-CO-), ester (-CO-O-), or carbonate groups (-OCO-O-), it is possible to study the effect of these additional links on the separation properties. Figure 8 shows the feed and permeate signals using a PC, PEEK, and PES membrane. In all membranes permeability to $\mathrm{H}_{2}$ can be observed. For the PC membrane, we additionally observed a signal when exposed to $30 \mathrm{ppm} \mathrm{CO}$. However, the sensor signal is very low at 1.04. The dimethyl group in PC leads to an increase in the distances between adjacent macromolecules. The PC has a lower density than PEEK and PES. It can therefore be assumed that the increased distances in combination with the weak polar carbonate group favor the permeability for CO. Concerning their permeability for $\mathrm{H}_{2}$, the sensor signals increase in the order of PES $<\mathrm{PC}<\mathrm{PEEK}$.

Thus, the highly polar sulfone groups $\left(-\mathrm{SO}_{2}^{-}\right)$in PES result in an increase of the retention capacity compared to $\mathrm{H}_{2}$, while the angled carbonate groups (-O-CO-O-) in $\mathrm{PC}$ and the alternating ether (-O-) and ketone (-CO-) groups in PEEK favor permeability to $\mathrm{H}_{2}$. We now consider the feed and permeate signals of PET and PEN membranes in Figure 9. 


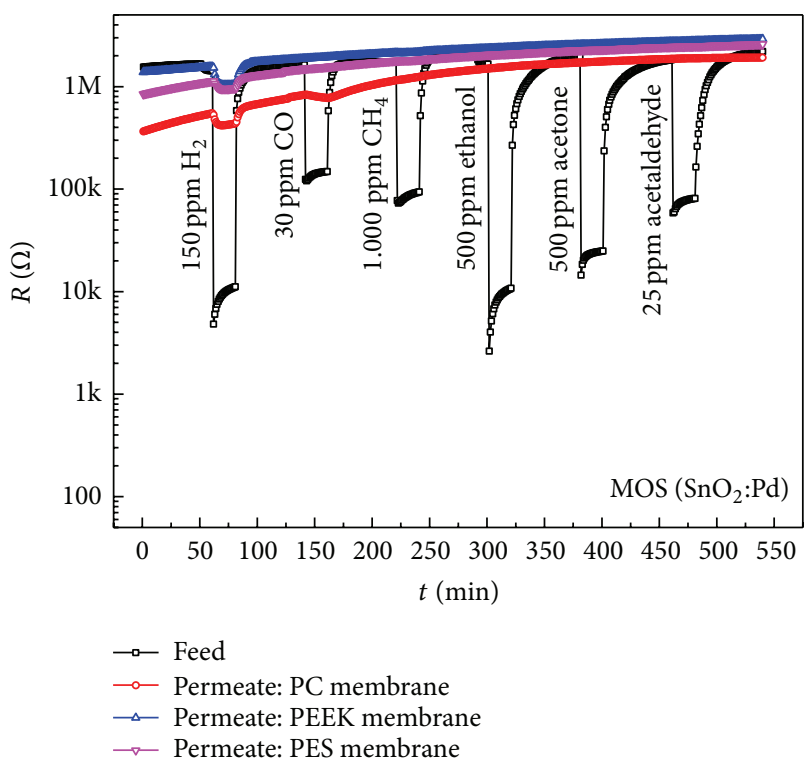

(a)<smiles>CC(C)(C)OC(=O)Oc1ccc(C(C)(C)c2ccc(C(C)(C)C)cc2)cc1</smiles><smiles>CC(C)CC(C)(C)Oc1ccc(Oc2ccc(C(=O)c3ccc(C(F)(F)F)cc3)cc2)cc1</smiles><smiles>CC(C)(C)Oc1ccc(S(=O)(=O)c2ccc(C(C)(C)C)cc2)cc1</smiles>

(b)

FIGURE 8: Separation properties of PC, PEEK, and PES upon exposure to $150 \mathrm{ppm} \mathrm{H}_{2}, 30 \mathrm{ppm} \mathrm{CO}, 1,000 \mathrm{ppm} \mathrm{CH}_{4}, 500 \mathrm{ppm}$ ethanol, $500 \mathrm{ppm}$ acetone, and $25 \mathrm{ppm}$ acetaldehyde. The diameter of the membranes is $6.4 \mathrm{~mm}$.

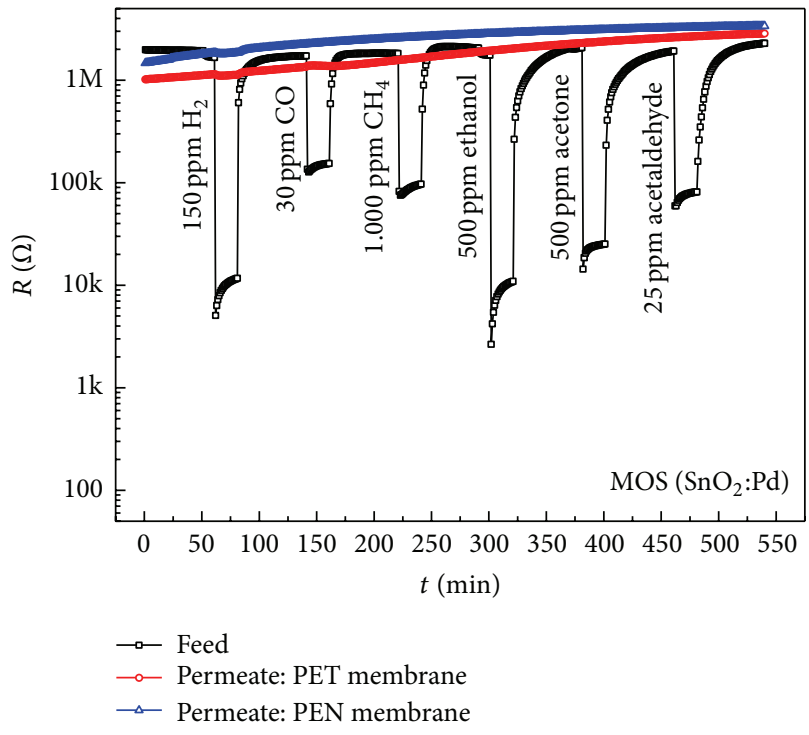

(a)<smiles>CCCNC(C)(C)OCCOC(=O)c1ccc2cc(C(=O)OCCOC(C)(C)C)ccc2c1</smiles>

(b)

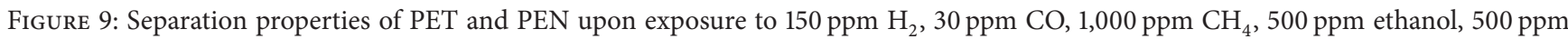
acetone, and $25 \mathrm{ppm}$ acetaldehyde. The diameter of the membranes is $6.4 \mathrm{~mm}$.

The structure of these macromolecules allows much higher chain flexibility due to the flexible $\mathrm{CH}_{2}$ groups. Unlike PC, PEEK, and PES, PET and PEN contain ester groups (-CO-O-) in the backbone. In ester groups carboxyl oxygen is bonded directly to the carbonyl group. This results in a delocalization of the charge of the carboxyl oxygen towards the electronwithdrawing carbonyl oxygen. So the polarization is lower than that of a ketone group but higher than that of an ether group. Because ester groups are present only in PET and PEN as a component of the macromolecules, these membranes are more polar than membranes made of PC, PEEK, and PES. Through their relatively long chains between the aromatic groups, membranes of PET and PEN have a higher density than membranes of PC and PEEK and thus lower interatomic distances. This explains the low gas permeability of these membranes compared to the already examined PC, PEEK, and PES.

In addition to the already discussed PES membrane from the group consisting of polyarylsulfones, the separation properties of nitrogen-thermoplastics, in which aliphatic or 


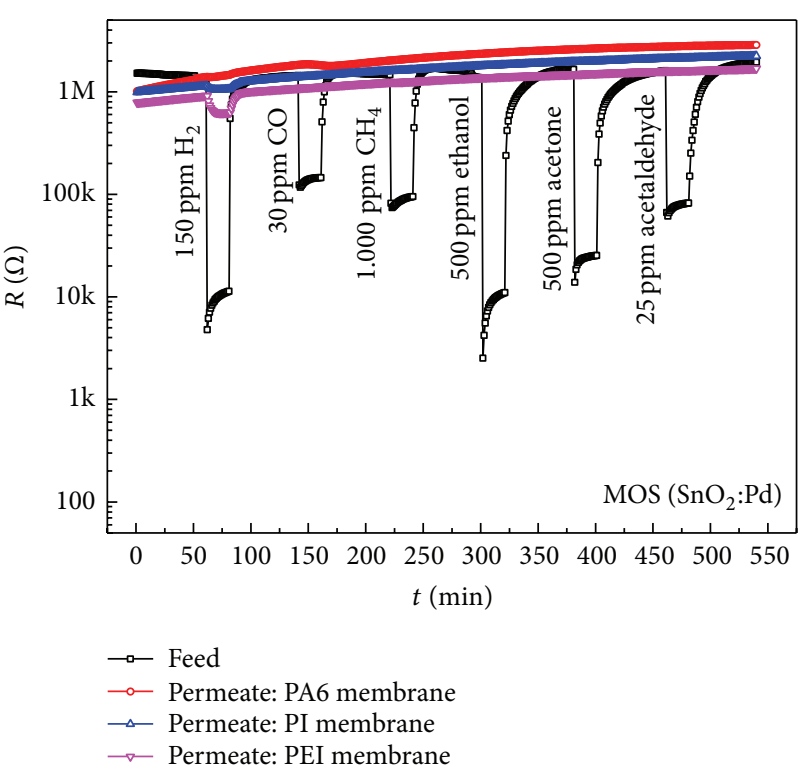<smiles>CCC(=O)CCCCCNC(C)(C)C</smiles>

PI:<smiles>CC(C)(C)c1ccc(Oc2ccc(-n3c(=O)c4cc5c(=O)n(C(C)(C)C)c(=O)c5cc4c3=O)cc2)cc1</smiles>

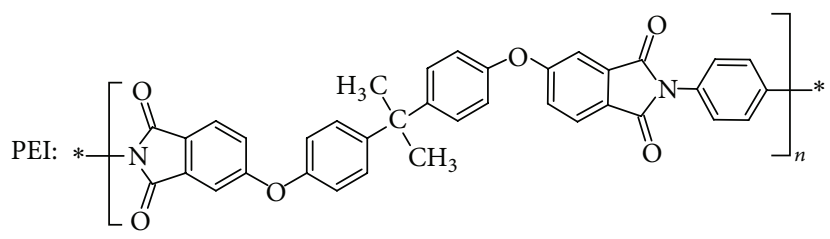

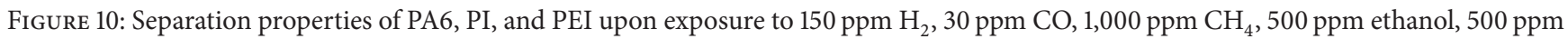
acetone, and $25 \mathrm{ppm}$ acetaldehyde. The diameter of the membranes is $6.4 \mathrm{~mm}$.

cycloaliphatic or aromatic chain links are disrupted by amide (PA6) or imide groups (PI, PEI), were examined more closely. The feed and the permeate signals of these membranes are plotted in Figure 10. Aliphatic polyamides are constructed from methylene- $\left(-\mathrm{CH}_{2}-\right)$ and amide groups (-CO-NH-). This causes two types of partial valency forces between the macromolecules. These are dispersion forces between the methylene groups and hydrogen bridge bonds between the amide groups. The properties of PA are very strongly influenced by the ratio of methylene and amide groups. With an increasing number of methylene groups, the polarity, the density, and the melting point of the polyamides decrease. The number of methylene groups in the PA6 membrane used is five. Due to the small number of methylene groups and the difference between the electronegativity of the $\mathrm{NH}$ bond of 0.9 and the $\mathrm{C}=0$ bond of 1.0, PA6 is strongly polar. Thereby, the membrane shows for acetaldehyde a very high retention capacity for $150 \mathrm{ppm} \mathrm{H}_{2}, 30 \mathrm{ppm} \mathrm{CO}, 1,000 \mathrm{ppm} \mathrm{CH}_{4}$, $500 \mathrm{ppm}$ ethanol, $500 \mathrm{ppm}$ acetone, and $25 \mathrm{ppm}$ acetaldehyde. Since this thermoplastic contains only ketone-groups, our assumption that the permeability for nonpolar gases is favored in polymers containing ether groups is verified again.

Also the thermoplastics PI and PEI are considerably polar due to the electron-withdrawing of the two carbonyl groups (-M effect). The monomers of these membranes contain, unlike PA6, one (in PI) or two (in PEI) ether groups. Considering the permeate signals of these membrane upon exposure with $150 \mathrm{ppm} \mathrm{H}_{2}$ we see that, with increasing number of ether groups, the permeability for $\mathrm{H}_{2}$ increases, while the gases $\mathrm{CO}, \mathrm{CH}_{4}$, ethanol, acetone, and acetaldehyde are completely retained. The sensor signal of the MOX sensor is 1.5 for the PEI membrane, which is slightly above the signal obtained with the PEEK membrane. The monomers of the PEEK membrane contain two ether groups, just as the PEI. The slightly increased permeability of the PEI membrane for $\mathrm{H}_{2}$ is explained by the increased distances between adjacent macromolecules by the dimethyl group. The feed signals of the tested thermoplastic polycondensates are summarized in Table 5.

The retention capacities of the membranes determined with the aid of the MOX sensor are summarized in the Table 6. Since for the PET, PEN, and PA6 membranes no signals were observed in the feed, they are not listed in the table. Table 7 gives the change of the absolute humidity in the permeate for the thermoplastic polycondensates PC, PEEK, PES, PET, PEN, PA6, PI, and PEI.

The thermoplastic polycondensates were further investigated with increased concentrations of the gases $\mathrm{CO}$ (100 ppm) and $\mathrm{CH}_{4}(3.000 \mathrm{ppm})$, as well as the nonpolar gases $\mathrm{NO}_{2}(1 \mathrm{ppm})$ and $\mathrm{CO}_{2}(1 \mathrm{vol} \%)$. Figure 11 shows the results of the measurement. An increase of the concentration is equal to an increase in the area or a reduction of the film thickness. In PET, PEN, and PA6, showing very high barrier properties when exposed to $150 \mathrm{ppm}_{2}, 30 \mathrm{ppm}$ $\mathrm{CO}, 1,000 \mathrm{ppm} \mathrm{CH}_{4}, 500 \mathrm{ppm}$ ethanol, $500 \mathrm{ppm}$ acetone, and $25 \mathrm{ppm}$ acetaldehyde, increased concentrations do not 
TABLE 5: Permeate signals of the MOX sensor using PC, PEEK, PES, PET, PEN, PA6, PI, and PEI membranes. The values given are the arithmetic mean of three measurements.

\begin{tabular}{|c|c|c|c|c|c|c|c|}
\hline Membrane & Sensor & $\mathrm{H}_{2}$ & $\mathrm{CO}$ & $\mathrm{CH}_{4}$ & Ethanol & Acetone & Acetald. \\
\hline PC & MOX & 1,3 & 1,04 & - & - & - & - \\
\hline PEEK & MOX & 1,4 & - & - & - & - & - \\
\hline PES & MOX & 1,2 & - & - & - & - & - \\
\hline PET & MOX & - & - & - & - & - & - \\
\hline PEN & MOX & - & - & - & - & - & - \\
\hline PA6 & MOX & - & - & - & - & - & - \\
\hline PI & MOX & 1,1 & - & - & - & - & - \\
\hline PEI & MOX & 1,5 & - & - & - & - & - \\
\hline
\end{tabular}

TABLE 6: Retention capacity of the investigated thermoplastic polycondensates PC, PEEK, PES, PI, and PEI. The values given are the arithmetic mean of three measurements.

\begin{tabular}{lcccccc}
\hline Membrane & Sensor & $\mathrm{H}_{2}$ & $\mathrm{CO}$ & $\mathrm{CH}_{4}$ & Ethanol & Acetone \\
\hline PC & MOX & $\mathbf{0 , 9 9 8}$ & 0,995 & - & - & - \\
PEEK & MOX & $\mathbf{0 , 9 9 7}$ & - & - & - & - \\
PES & MOX & $\mathbf{0 , 9 9 9 1}$ & - & - & - & - \\
PI & MOX & 0,9997 & - & - & - & - \\
PEI & MOX & $\mathbf{0 , 9 9 6}$ & - & - & - & - \\
\hline
\end{tabular}

TABLE 7: Change of the absolute humidity in the permeate for the thermoplastic polycondensates PC, PEEK, PES, PET, PEN, PA6, PI, and PEI. The concentrations in the feed and permeate were measured with a digital T/RH sensor (HYT221).

\begin{tabular}{|c|c|c|c|c|c|}
\hline Membrane & Sensor & $\Delta A_{\text {Feed }}\left[\mathrm{g} / \mathrm{m}^{3}\right]$ & $\Delta B_{\text {Feed }}\left[\mathrm{g} / \mathrm{m}^{3}\right]$ & $\Delta A_{\text {Permeat }}\left[\mathrm{g} / \mathrm{m}^{3}\right]$ & $\Delta B_{\text {Permeat }}\left[\mathrm{g} / \mathrm{m}^{3}\right]$ \\
\hline PC & HYT221 & 5 & 9,6 & 2,2 & 4,2 \\
\hline PEEK & HYT221 & 4,6 & 9 & 1,1 & 2,2 \\
\hline PES & HYT221 & 4,5 & 9 & 3,1 & 6 \\
\hline PET & HYT221 & 5,3 & 10,1 & 0,9 & 1,8 \\
\hline PEN & HYT221 & 4,8 & 9,7 & 0,1 & 0,2 \\
\hline PA6 & HYT221 & 4,6 & 9,1 & 1,1 & 3,4 \\
\hline PI & HYT221 & 4,6 & 9,1 & 1,3 & 2,6 \\
\hline PEI & HYT221 & 4,6 & 9 & 1,3 & 2,7 \\
\hline
\end{tabular}

cause any higher permeate signals. In contrast, minimal signals were observed for 3,000 $\mathrm{ppm} \mathrm{CH}_{4}$ in the $\mathrm{H}_{2}$-selective membranes PC, PEEK, PES, PI, and PEI.

The highest permeability to $\mathrm{CH}_{4}$ showed the PEEK and PEI membranes. Thus, these membranes are modified (layer thickness, area); a high selectivity towards $\mathrm{CH}_{4}$ can be achieved (in the absence of $\mathrm{H}_{2}$ ). To investigate the permeation of water vapor, the absolute humidity was increased in two steps of $4.8 \mathrm{~g} / \mathrm{m}^{3}$, just as for the polyolefins, and measured for two hours each. The measured concentrations in the feed and permeate are plotted in Figure 12.

With the exception of PEN, the permeability to water vapor in all thermoplastic polycondensates is higher than the permeability of polyolefins. It is striking that the amorphous thermoplastics PC, PI, PEI, and PES have a significantly higher permeability to water vapor than the examined thermoplastics PET, PEN, and PEEK with partially crystalline regions. An exception is the AB-polyamide PA6. With 2.7 M\%, it has the highest water absorption of all investigated thermoplastics.
The number of $-\mathrm{CH}_{2}$ groups between the recurring carbonamide groups in PA6 is five. In the linear PA6 macromolecules only every second functional group allows a hydrogen bond. This leads to increased water absorption. But interestingly the PA6 shows no permeability when exposed to the gases $\mathrm{H}_{2}, \mathrm{CO}, \mathrm{CH}_{4}$, ethanol, acetone, acetaldehyde, $\mathrm{NO}_{2}$, and $\mathrm{CO}_{2}$.

\section{Summary and Outlook}

Our results can thus be summarized as follows. In the examined nonpolar polyolefins, the macromolecules are held together only by weak dispersion forces. The strength of the bond is about $1 / 500$ to $1 / 1000$ of a primary valency bond. Therefore the separation characteristics are primarily based on the arrangement and cross-linking of the macromolecules. Dispersion forces are most pronounced in the highly ordered crystalline domains. The degree of crystallization of the membrane increases in the order LDPE $<$ PMP $<$ PP $<$ HDPE. The degree of crystallization influences the permeability and 


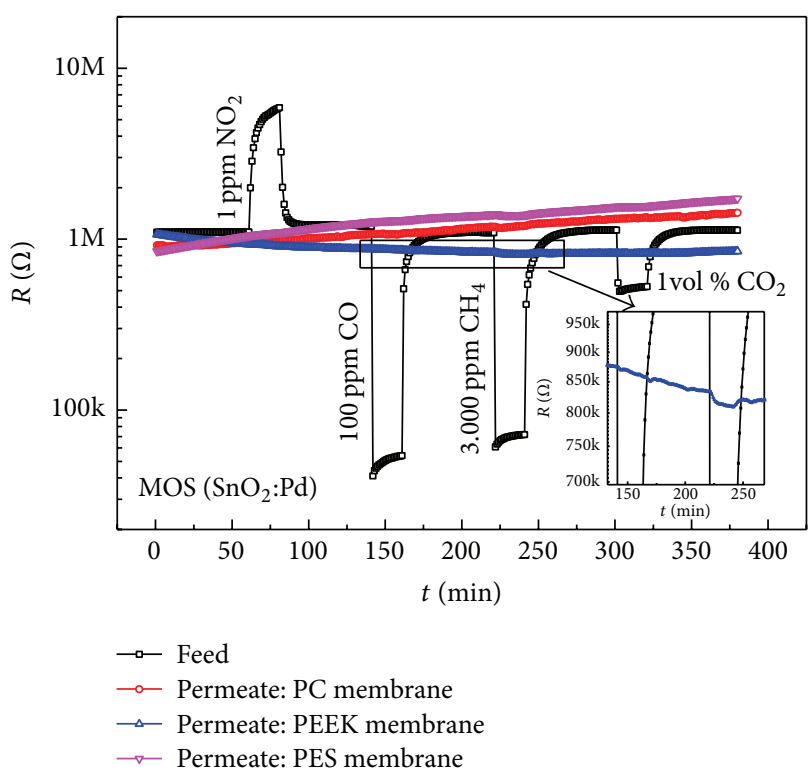

(a)

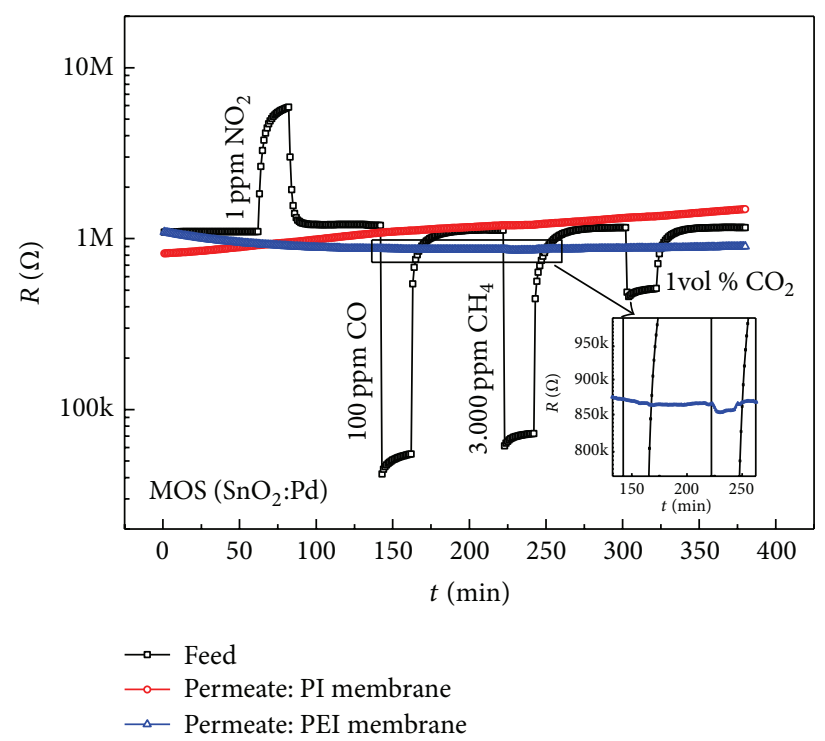

(b)

FIGURE 11: Separation characteristics of the membranes PC, PEEK, and PES (a) and PI and PEI (b) during the exposure to an increased concentration of $\mathrm{CO}(100 \mathrm{ppm})$ and $\mathrm{CH}_{4}(3,000 \mathrm{ppm})$ and $1 \mathrm{ppm} \mathrm{NO}$ and $1 \mathrm{vol} \% \mathrm{CO}_{2}$. The diameter of the membranes is $6.4 \mathrm{~mm}$.
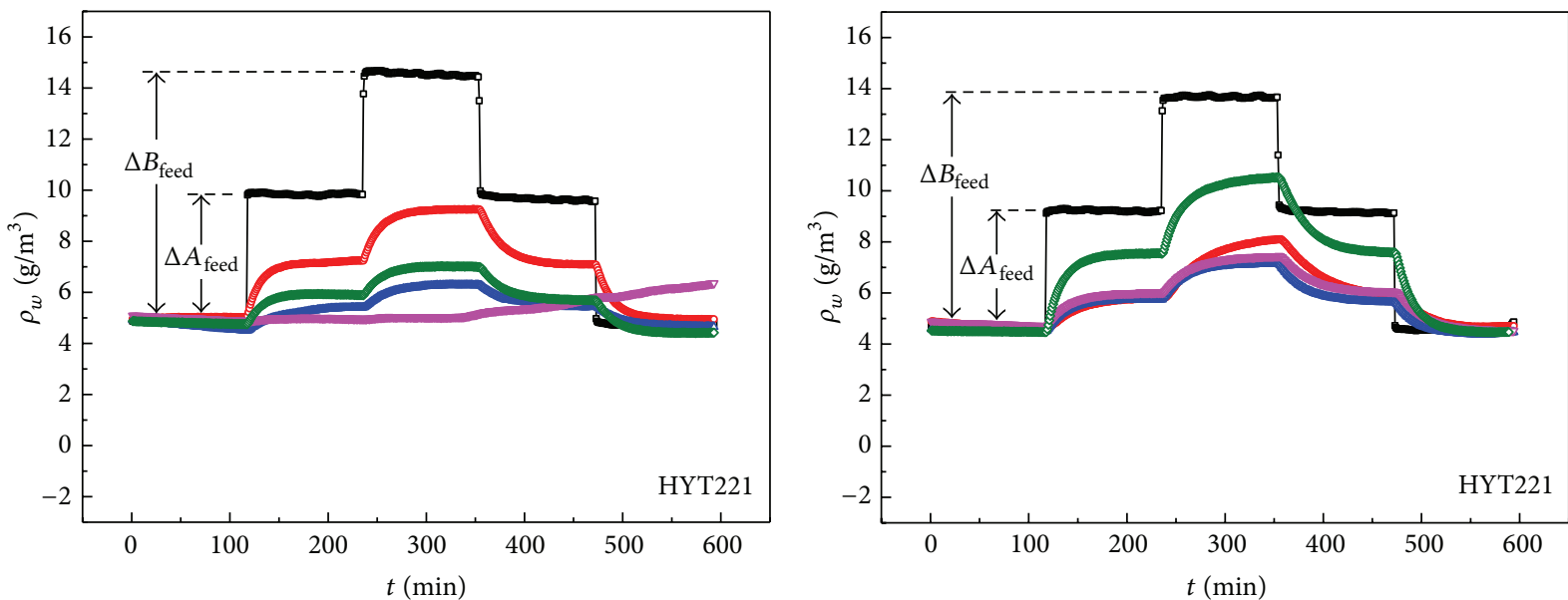

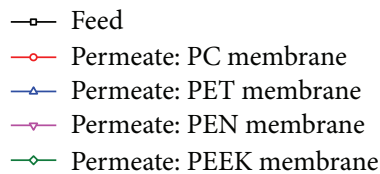

(a)

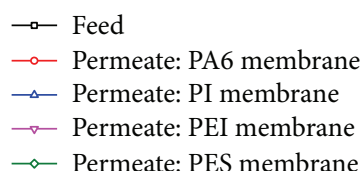

(b)

FIgURE 12: (a) Water vapor permeability of PC, PET, PEN, and PEEK membranes. (b) Water vapor permeability of PA6, PI, PEI, and PES membranes. The absolute humidity is increased in two steps of $4.8 \mathrm{~g} / \mathrm{m}^{3}(\Delta A, \Delta B)$.

selectivity of a polymer membrane. Increasing degree of crystallinity (increasing density) increases selectivity, while the permeability or solubility decreases with the increase of the crystalline domains. However, this is not valid in general, since certain polymers have a specific permeability to chemically similar construction gases or vapors. Through the introduction of side chains, the interatomic distances between adjacent macromolecules are larger. This leads to a decrease in density. The density of the membrane thus decreases in the order of PE + graphite > HDPE > LDPE $>$ PP > PMP. A low density is synonymous with larger atomic distances. This results in higher gas permeability. The measurements have shown that, with decreasing density, the retention capacity of the membrane increases, contrary to expectations. We assume that this effect is related to the chain structure, since the macromolecules in PP and PMP 
form $3_{1}$ helices in contrast to the PE-types. The investigated polyolefins both show permeability to nonpolar and polar gases and are not very selective, with the exception of HDPE. In principle, the nonpolar polyolefins would have higher permeability to nonpolar material components. This was not observed in our study. In the HDPE membrane, the retention capacity for ethanol, acetaldehyde, $\mathrm{CO}, \mathrm{H}_{2}$, and $\mathrm{CH}_{4}$ is significantly higher than that for acetone. Thus, high acetone selectivity can be achieved by a modification (increase in layer thickness or reduction of the area) of this membrane. The class of polyolefins includes not only nonpolar polymers but also a variety of polar polymers. The investigation of the separation properties of LDPE, HDPE, $\mathrm{PE}+$ graphite, $\mathrm{PP}$, and $\mathrm{PMP}$ has revealed an increased retention of nonpolar gases and water vapor. We therefore suppose that in a slightly polarized membrane (inductive effect), the transmittance for nonpolar gases is increased. Interesting materials for further studies would be, for example, polyvinyl chloride (PVC), ethylene/vinyl acetate copolymers (EVAC), ethylene/vinyl alcohol copolymers (EVOH), ethylene/ethyl acrylate copolymers (EEAK), or polyoxymethylene (POM) and polymethyl methacrylate (PMMA) from the substance group of polyacrylates or polyacetals. Another possibility is to chemically further modify PE. Firstly, PE can be cross-linked via high-energy $\beta$ - or $\gamma$-radiation, peroxide, or azo or silane cross-linking (PE-X). Secondly, the surface can be chemically modified by chlorinating with radical formers (PE-C) or corrosive gases such as fluorine $\left(\mathrm{F}_{2}\right)$ or sulfur trioxide $\left(\mathrm{SO}_{3}\right)$ [61].

The membranes PC, PEEK, PES, PI, and PEI are highly selective to $\mathrm{H}_{2}$. The gases $\mathrm{CO}$, ethanol, acetone, acetaldehyde, $\mathrm{NO}_{2}$, and $\mathrm{CO}_{2}$ were completely retained by the membranes at the specified concentrations. The presence of ether groups in the backbone facilitates the permeability of $\mathrm{H}_{2}$. The highest permeate signals were obtained using the PEEK and PEI membrane. Thus, when exposed to $\mathrm{H}_{2}$, the height of the sensor signals correlates with the number of ether groups. Upon exposure with an increased methane concentration of 3,000 ppm, a slight transmittance is observed in the membranes of PC, PEEK, PES, PI, and PEI. The highest permeabilities showed the membranes made of PEEK and PEI. A reduction of the layer thickness or an enlargement of the area should lead to a high selectivity towards $\mathrm{CH}_{4}$ in the absence of $\mathrm{H}_{2}$. The measurements have shown that even highly polar polymers with sufficient nonpolar areas in the backbone are very selective towards nonpolar gases. With the exception of PEN, the permeability to water vapor is in all investigated thermoplastic polycondensates higher than in polyolefins. It is striking that the amorphous thermoplastics PC, PI, PEI, and PES have a significantly higher permeability to water vapor than the examined thermoplastics PET, PEN, and PEEK with partially crystalline regions. Amorphous polymers have a larger number of cavities and thus an enlarged permeability in comparison to semicrystalline polymers. An exception is the aliphatic PA6. With its small number of methylene groups, this membrane shows very high barrier properties against the gases $\mathrm{H}_{2}, \mathrm{CO}, \mathrm{CH}_{4}$, ethanol, acetone, acetaldehyde, $\mathrm{NO}_{2}$, and $\mathrm{CO}_{2}$ but has, interestingly enough, very high water vapor permeability. With an increasing number of methylene groups, the gas permeability of aliphatic polyamides should rise. Other interesting membranes would thus be the polyamides PA11, PA12, PA610, and PA612. Since the permeability for nonpolar gases is promoted by ether groups, for example, polyphenylene ether (PPE) and polyphenylene oxide (PPO) should have good separation properties.

\section{Conflict of Interests}

The authors declare that there is no conflict of interests regarding the publication of this paper.

\section{References}

[1] P. Gründler, Chemische Sensoren: Eine Einführung für Naturwissenschaftler und Ingenieure, Springer, Berlin, Germany, 2004.

[2] P. Hauptmann, Sensoren: Prinzipien und Anwendungen, Hanser Publishers, Munich, Germany, 1990.

[3] E. Hering and G. Schönfelder, Sensoren in Wissenschaft und Technik: Funktionsweise und Einsatzgebiete, Vieweg+Teubner, Wiesbaden, Germany, 2012.

[4] C. O. Park and S. A. Akbar, "Ceramics for chemical sensing," Journal of Materials Science, vol. 38, no. 23, pp. 4611-4637, 2003.

[5] S. Akbar, P. Dutta, and C. Lee, "High-temperature ceramic gas sensors: a review," International Journal of Applied Ceramic Technology, vol. 3, no. 4, pp. 302-311, 2006.

[6] C. Pijolat, J. P. Viricelle, G. Tournier, and P. Montmeat, "Application of membranes and filtering films for gas sensors improvements," Thin Solid Films, vol. 490, no. 1, pp. 7-16, 2005.

[7] N. B. McKeown and P. M. Budd, "Polymers of intrinsic microporosity," in Encyclopedia of Membrane Science and Technology, E. M. V. Hoek and V. V. Tarabara, Eds., vol. 2, pp. 781-797, John Wiley \& Sons, Hoboken, NJ, USA, 2013.

[8] M. Barboiu, "Constitutional dynameric networks for membranes," in Ecyclopedia of Membrane Science and Technology, E. M. V. Hoek and V. V. Tarabara, Eds., vol. 2, pp. 945-963, John Wiley \& Sons, Hoboken, NJ, USA, 2013.

[9] E. Favre, "Polymeric membranes for gas separation," in Comprehensive Membrane Science and Engineering: Membrane Operations in Molecular Separations, E. Drioli and L. Giorno, Eds., vol. 2, pp. 155-212, Elsevier, Kidlington, UK, 2010.

[10] H. Buschatz, B. Dageförde, K. Jakoby, K.-V. Peinemann, and D. Paul, "Hochselektive stofftrennungen mit carriermembranenstand der entwicklung und erwartungen," Chemie Ingenieur Technik, vol. 73, no. 4, pp. 297-303, 2001.

[11] A. Raza and B. Ding, "Superhydrophobic biomimetic fibrous membranes," in Encyclopedia of Membrane Science and Technology, E. M. V. Hoek and V. V. Tarabara, Eds., vol. 2, pp. 984-1021, John Wiley \& Sons, Hoboken, NJ, USA, 2013.

[12] M. Ulbricht, "Oberflächenmodifikation," in Membranen: Grundlagen, Verfahren und Industrielle Anwendungen, K. Ohlrogge and K. Ebert, Eds., chapter 3, pp. 47-75, Wiley-VCH, Weinheim, Germany, 2006.

[13] Y. Fang, Z.-K. Xu, and J. Wu, "Surface modification of membranes," in Encyclopedia of Membrane Science and Technology, E. M. V. Hoek and V. V. Tarabara, Eds., vol. 1, pp. 460-474, John Wiley \& Sons, Hoboken, NJ, USA, 2013.

[14] S. Ramakrishna, Z. Ma, and T. Matsuura, Polymer membranes in Biotechnology: Preparation, Functionalization and Application, edited by: S. Ramakrishna, Z. Ma, T. Matsuura, chapter 3-4, Imperial College Press, London, UK, 2011. 
[15] H. B. Park, "Gas separation membranes," in Encyclopedia of Membrane Science and Technology, E. M. V. Hoek and V. V. Tarabara, Eds., vol. 1, pp. 139-171, John Wiley \& Sons, Hoboken, NJ, USA, 2013.

[16] B. T. Low, Y. Wang, and T.-S. Chung, "Polymeric membranes for energy applications," in Encyclopedia of Membrane Science and Technology, E. M. V. Hoek and V. V. Tarabara, Eds., vol. 3, pp. 2066-2102, John Wiley \& Sons, Hoboken, Nj, USA, 2066.

[17] R. Rego, N. Caetano, and A. Mendes, "Hydrogen/methane and hydrogen/nitrogen sensor based on the permselectivity of polymeric membranes," Sensors and Actuators B: Chemical, vol. 111-112, pp. 150-159, 2005.

[18] S. Kitsukawa, H. Nakagawa, K. Fukuda, S. Asakura, S. Takahashi, and T. Shigemori, "Interference elimination for gas sensor by catalyst filters," Sensors and Actuators B: Chemical, vol. 65, no. 1-3, pp. 120-121, 2000.

[19] P. Althainz, A. Dahlke, M. Frietsch-Klarhof, J. Goschnick, and H. J. Ache, "Reception tuning of gas-sensor microsystems by selective coatings," Sensors and Actuators B: Chemical, vol. 25, no. 1-3, pp. 366-369, 1995.

[20] M. Fleischer, S. Kornely, T. Weh, J. Frank, and H. Meixner, "Selective gas detection with high-temperature operated metal oxides using catalytic filters," Sensors and Actuators B: Chemical, vol. 69, no. 1, pp. 205-210, 2000.

[21] T. Weh, M. Fleischer, and H. Meixner, "Optimization of physical filtering for selective high temperature $\mathrm{H}_{2}$ sensors," Sensors and Actuators B: Chemical, vol. 68, no. 1-3, pp. 146-150, 2000.

[22] A. Cabot, J. Arbiol, A. Cornet, J. R. Morante, F. Chen, and M. Liu, "Mesoporous catalytic filters for semiconductor gas sensors," Thin Solid Films, vol. 436, no. 1, pp. 64-69, 2003.

[23] C. H. Kwon, D. H. Yun, H.-K. Hong et al., "Multi-layered thickfilm gas sensor array for selective sensing by catalytic filtering technology," Sensors and Actuators B: Chemical, vol. 65, no. 1-3, pp. 327-330, 2000.

[24] M. Vilaseca, J. Coronas, A. Cirera, A. Cornet, J. R. Morante, and J. Santamaría, "Use of zeolite films to improve the selectivity of reactive gas sensors," Catalysis Today, vol. 82, no. 1-4, pp. 179$185,2003$.

[25] G. Hagen, A. Dubbe, F. Rettig et al., "Selective impedance based gas sensors for hydrocarbons using ZSM-5 zeolite films with chromium(III)oxide interface," Sensors and Actuators B: Chemical, vol. 119, no. 2, pp. 441-448, 2006.

[26] O. Hugon, M. Sauvan, P. Benech, C. Pijolat, and F. Lefebvre, "Gas separation with a zeolite filter, application to the selectivity enhancement of chemical sensors," Sensors and Actuators B: Chemical, vol. 67, no. 3, pp. 235-243, 2000.

[27] K. Sahner, D. Schönauer, P. Kuchinke, and R. Moos, “Zeolite cover layer for selectivity enhancement of p-type semiconducting hydrocarbon sensors," Sensors and Actuators, B: Chemical, vol. 133, no. 2, pp. 502-508, 2008.

[28] A. Afonja, S. Dungey, R. Binions, I. Parkin, D. Lewis, and D. Williams, "Gas sensing properties of composite tungsten trioxide-zeolite thick films," ECS Transactions, vol. 16, no. 24, pp. 77-84, 2009.

[29] R. Binions, H. Daviesa, A. Afonja, and et al, "Zeolite modified discriminating gas sensors," Journal of The Electrochemical Society, vol. 156, no. 3, pp. J46-J51, 2009.

[30] R. Binions, A. Afonja, S. Dungey, D. Lewis, I. Parkin, and D. E. Williams, "Zeolite modification. Towards discriminating metal oxide gas sensors," ECS Transactions, vol. 19, no. 6, pp. 241-250, 2008.
[31] M. Hübner, A. Yuece, G. C. Mondragón Rodríguez, B. Saruhan, N. Barsan, and U. Weimar, "BaTi ${ }_{0,95} \mathrm{Rh}_{0,05} \mathrm{O}_{3}$ catalytic filter layer-a promising candidate for the selective detection of $\mathrm{CO}$ in the presence of $\mathrm{H}_{2}$," Procedia Engineering, vol. 5, pp. 107-110, 2010.

[32] S. Ajami, Y. Mortazavi, A. Khodadadi, F. Pourfayaz, and S. Mohajerzadeh, "Highly selective sensor to $\mathrm{CH}_{4}$ in presence of $\mathrm{CO}$ and ethanol using $\mathrm{LaCoO}_{3}$ perovskite filter with $\mathrm{Pt} / \mathrm{SnO}_{2}$," Sensors and Actuators B: Chemical, vol. 117, no. 2, pp. 420-425, 2006.

[33] A. Ryzhikov, M. Labeau, and A. Gaskov, " $\mathrm{Al}_{2} \mathrm{O}_{3}(\mathrm{M}=\mathrm{Pt}, \mathrm{Ru})$ catalytic membranes for selective semiconductor gas sensors," Sensors and Actuators B: Chemical, vol. 109, no. 1, pp. 91-96, 2005.

[34] J. Hubálek, K. Malysz, J. Prášek et al., "Pt-loaded $\mathrm{Al}_{2} \mathrm{O}_{3}$ catalytic filters for screen-printed $\mathrm{WO}_{3}$ sensors highly selective to benzene," Sensors and Actuators B: Chemical, vol. 101, no. 3, pp. 277-283, 2004.

[35] M. Frietsch, F. Zudock, J. Goschnick, and M. Bruns, "CuO catalytic membrane as selectivity trimmer for metal oxide gas sensors," Sensors and Actuators B: Chemical, vol. 65, no. 1-3, pp. 379-381, 2000.

[36] S. Liu, X. Tan, and K. Li, "Inorganic membranes," in Encyclopedia of Membrane Science and Technology, E. M. V. Hoek and V. V. Tarabara, Eds., vol. 1, pp. 610-638, John Wiley \& Sons, Hoboken, NJ, USA, 2013.

[37] C. Yacou, D. Wang, J. Motuzas, X. Zhang, S. Smart, and J. C. D. da Costa, "Thin-film ceramic membranes," in Encyclopedia of Membrane Science and Technology, E. M. V. Hoek and V. V. Tarabara, Eds., vol. 1, pp. 676-711, John Wiley \& Sons, Hoboken, NJ, USA, 2013.

[38] S. Basu, A. Cano-Odena, and I. F. J. Vankelecom, "Asymmetric Matrimid/ $\left[\mathrm{Cu}_{3}(\mathrm{BTC})_{2}\right]$ mixed-matrix membranes for gas separations," Journal of Membrane Science, vol. 362, no. 1-2, pp. 478487, 2010.

[39] P. S. Tin, T. S. Chung, Y. Liu, R. Wang, S. L. Liu, and K. P. Pramoda, "Effects of cross-linking modification on gas separation performance of Matrimid membranes," Journal of Membrane Science, vol. 225, no. 1-2, pp. 77-90, 2003.

[40] Y. Zhang, I. H. Musselman, J. P. Ferraris, and K. J. Balkus Jr., "Gas permeability properties of Matrimid membranes containing the metal-organic framework Cu-BPY-HFS," Journal of Membrane Science, vol. 313, no. 1-2, pp. 170-181, 2008.

[41] R. Adams, J. R. Johnson, C. Zhang et al., "Mixed-matrix membranes," in Encyclopedia of Membrane Science and Technology, E. M. V. Hoek and V. V. Tarabara, Eds., vol. 1, pp. 398-430, John Wiley \& Sons, Hoboken, NJ, USA, 2013.

[42] T. Melin and R. Rautenbach, Membranverfahren: Grundlagen der Modul- und Anlagenauslegung, vol. 3, Springer, Berlin, Germany, 2007.

[43] I. Voigt and S. Tudyka, "Keramische membranen und hohlfasern," in Membranen: Grundlagen, Verfahren und industrielle Anwendungen, K. Ohlrogge and K. Ebert, Eds., chapter 5, pp. 103-146, Wiley, Weinheim, Germany, 2006.

[44] K. Ohlrogge, J. Wind, and K.-V. Peinemann, "Verfahren zur trennung von gasen und dämpfen," in Membranen: Grundlagen, Verfahren und industrielle Anwendungen, K. Ohlrogge and K. Ebert, Eds., chapter 12, pp. 375-428, Wiley, Weinheim, Germany, 2006.

[45] X. He, Q. Yu, and M.-B. Hägg, " $\mathrm{CO}_{2}$ capture," in Encyclopedia of Membrane Science and Technology, E. M. V. Hoek and 
V. V. Tarabara, Eds., vol. 3, pp. 1560-1588, John Wiley \& Sons, Hoboken, NJ, USA, 2013.

[46] H. Lin, L. S. White, K. lokhandwala, and R. W. Baker, "Natural gas purification," in Encyclopedia of Membrane Science and Technology, E. M. V. Hoek and V. V. Tarabara, Eds., vol. 3, pp. 1644-1668, John Wiley \& Sons, Hoboken, NJ, USA, 2013.

[47] D. Rana and T. Matsuura, "Oxygen-nitrogen separation," in Encyclopedia of Membrane Science and Technology, E. M. V. Hoek and V. V. Tarabara, Eds., vol. 3, pp. 1668-1693, John Wiley \& Sons, Hoboken, NJ, USA, 2013.

[48] A. Brunetti, G. Barbieri, and E. Drioli, "Gas separation, applications," in Encyclopedia of Membrane Science and Technology, E. M. V. Hoek, V. V. Tarabara, and E. Drioli, Eds., vol. 3, pp. 18861915, John Wiley \& Sons, Hoboken, NJ, USA, 2013.

[49] Y. Yampolskii and B. Freeman, Membrane Gas Separation, John Wiley \& Sons, Chichester, UK, 2010.

[50] R. W. Baker, Membrane Technology and Application, edited by R. W. Baker, John Wiley \& Sons, Chichester, UK, 3rd edition, 2012.

[51] Y. Yampolskii, I. Pinnau, and B. Freeman, Material Science of Membranes for Gas and Vapor Separation, edited by Y. Yampolskii, I. Pinnau, and B. Freeman, John Wiley \& Sons, Chichester, UK, 2006.

[52] C. A. Scholes, S. E. Kentish, and G. W. Stevens, "The effects of minor components on the gas separation performance of polymetric membranes for carbon capture," in Membrane Gas Separation, Y. Yampolskii and B. Freeman, Eds., chapter 11, pp. 201-226, John Wiley \& Sons, Chichester, UK, 2010.

[53] H. E. A. Brüschke, "Pervaporation und dampfpermeation," in Membranen: Grundlagen, Verfahren und industrielle Anwendungen, K. Ohlrogge and K. Ebert, Eds., chapter 11, pp. 335-374, Wiley, Weinheim, Germany, 2006.

[54] A. Jonquières, C. Arnal-Herault, and J. Babin, "Pervaporation," in Encyclopedia of Membrane Science and Technology, E. M. V. Hoek and V. V. Tarabara, Eds., vol. 3, pp. 1533-1560, John Wiley \& Sons, Hoboken, NJ, USA, 2013.

[55] A. Brunetti, P. Bernardo, E. Drioli, and G. Barbieri, "Membrane engineering: progress and potentialities in gas separation," in Membrane Gas Separation, Y. Yampolskii and B. Freeman, Eds., chapter 14, pp. 281-312, John Wiley \& Sons, Chichester, UK, 2010.

[56] K. Nagai, "Fundamentals and perspectives for pervoparation," in Comprehensive Membrane Science and Engineering: Membrane Operations in Molecular Separations, E. Drioli and L. Giorno, Eds., vol. 2, pp. 243-271, Elsevier, Kidlington, UK, 2010.

[57] T. Uragami, "Selective membranes for purification and separation of organic liquid mixtures," in Comprehensive Membrane Science and Engineering: Membrane Operations in Molecular Separations, E. Drioli and L. Giorno, Eds., vol. 2, pp. 273-324, Elsevier, Kidlington, UK, 2010.

[58] D. Gorri, A. Urtiaga, and I. Ortiz, "Supported liquid membranes for pervaporation processes," in Comprehensive Membrane Science and Engineering: Membrane Operations in Molecular Separations, E. Drioli and L. Giorno, Eds., vol. 2, pp. 325-349, Elsevier, Kidlington, UK, 2010.

[59] R. W. Baker, Membrane Technology and Applications, edited by: R. W. Baker, chapter 8, John Wiley \& Sons, Chichester, UK, 3rd edition, 2012.

[60] H. Domininghaus, P. Elsner, P. Eyerer, and T. Hirth, Kunststoffe: Eigenschaften und Anwendungen, Edited by P. Elsner, P. Eyerer, and T. Hirth, Springer, Heidelberg, Germany, 8th edition, 2012.
[61] W. Kaiser, "Polyolefine," in Kunststoffchemie für Ingenieure: Von der Synthese bis zur Anwendung, W. Kaiser, Ed., chapter 4, pp. 235-272, Carl Hanser, München, Germany, 3rd edition, 2011.

[62] W. Hellerich, G. Harsch, and E. Baur, Werkstoff-Führer Kunststoffe: Eigenschaften, Prüfungen, Kennwerte, edited by W. Hellerich, G. Harsch, and E. Baur, Carl Hanser, München, Germany, 10th edition, 2010.

[63] W. Kaiser, Kunststoffchemie für Ingenieure: Von der Synthese bis zur Anwendung, vol. 3 of edited by W. Kaiser, Carl Hanser, München, Germany, 2011.

[64] H. Domininghaus, P. Elsner, P. Eyerer, and T. Hirth, Kunststoffe: Eigenschaften und Anwendungen, edited by: P. Elsner, P. Eyerer, T. Hirth, Springer, Heidelberg, Germany, 8th edition, 2012.

[65] E. Baur, S. Brinkmann, T. A. Osswald, N. Rudolph, and E. Schmachtenberg, Saechtling Kunststoff Taschenbuch, Edited by H. Saechtling, Carl Hanser, München, Germany, 31st edition, 2013.

[66] W. Hellerich, G. Harsch, and E. Baur, Werkstoff-Führer Kunststoffe: Eigenschaften, Prüfungen, Kennwerte, Edited by W. Hellerich, G. Harsch, and E. Baur, Carl Hanser, München, Germany, 10th edition, 2010.

[67] W. Keim, Kunststoffe: Synthese, Herstellungsverfahren, Apparaturen, Edited by W. Keim, Wiley, Weinheim, Germany, 2006.

[68] J. C. Cañadas, J. A. Diego, J. Sellarès et al., "Comparative study of amorphous and partially crystalline poly(ethylene-2,6naphthalene dicarboxylate) by TSDC, DEA, DMA and DSC," Polymer, vol. 41, no. 8, pp. 2899-2905, 2000.

[69] Goodfellow GmbH, 2013, http://www.goodfellow.com/.

[70] Reichelt Chemietechnik GmbH \& Co, Thomaplast II Halbzeuge, Reichelt Chemietechnik GmbH \& Co, 2012, http://www.rctonline.de/.

[71] P. Meares, "The diffusion of gases through polyvinyl acetate," Journal of the American Chemical Society, vol. 76, no. 13, pp. 3415-3422, 1954.

[72] R. Bernstein, Y. Kaufman, and V. Freger, "Membrane characterization," in Encyclopedia of Membrane Science and Technology, E. M. V. Hoek and V. V. Tarabara, Eds., vol. 2, pp. 1021-1062, John Wiley \& Sons, Hoboken, NJ, USA, 2013.

[73] Y. M. Volfkovich, A. N. Filippov, and V. S. Bagotsky, Structural Properties of Porous Materials and Powders Used in Different Fields of Science and Technology, Edited by Y. M. Volfkovich, A. N. Filippov, and V.S. Bagotsky, Springer, London, UK, 2014.

[74] S. Matteucci, Y. Yampolskii, B. D. Fremann, and I. Pinnau, "Transport of gases and vapors in glassy and rubbery polymers," in Materials Science of Membranes for Gas and Vapor Separation, Y. Yampolskii, I. Pinnau, and B. D. Fremann, Eds., pp. 1-47, John Wiley \& Sons, Chichester, UK, 2006.

[75] H. Strathmann, Introduction to Membrane Science and Technology, edited by H. Strathmann, Wiley, Weinheim, Germany, 2011.

[76] T. Melin and R. Rautenbach, Membranverfahren: Grundlagen der Modul- und Anlagenauslegung, edited by: T. Melin, R. Rautenbach, Springer, Berlin, Germany, 3rd edition edition, 2007.

[77] J. Kappler, Characterisation of high-performance $\mathrm{SnO}_{2}$ gas sensors for CO detection by in situ techniques [Ph.D. dissertation], Fakultät für Chemie und Pharmazie, Universität Tübingen, Tübingen, Germany, 2001. 


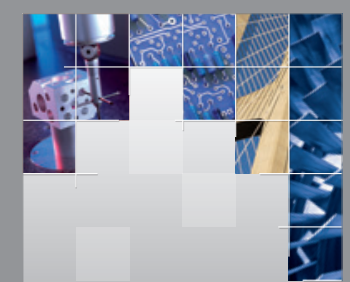

\section{Enfincering}
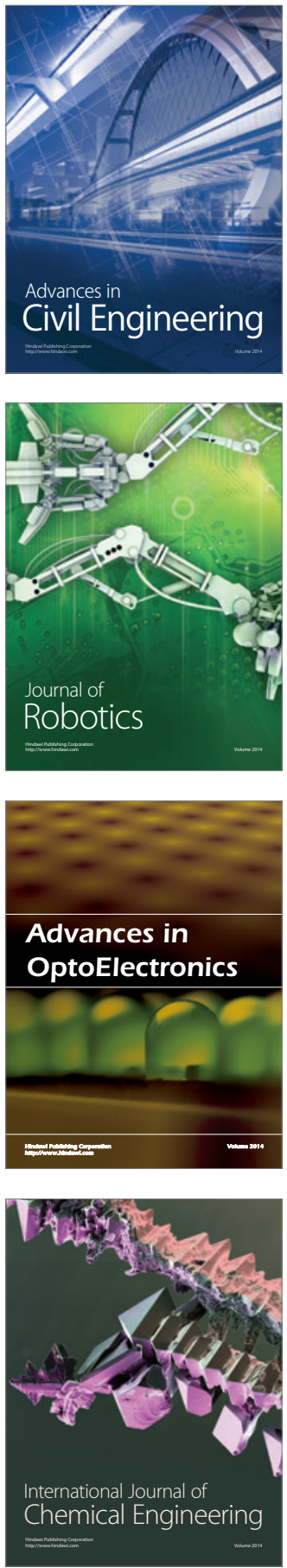

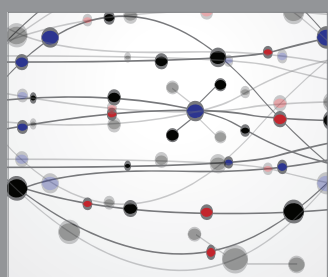

The Scientific World Journal

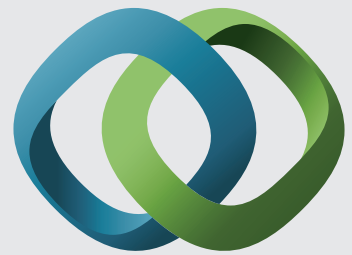

\section{Hindawi}

Submit your manuscripts at

http://www.hindawi.com
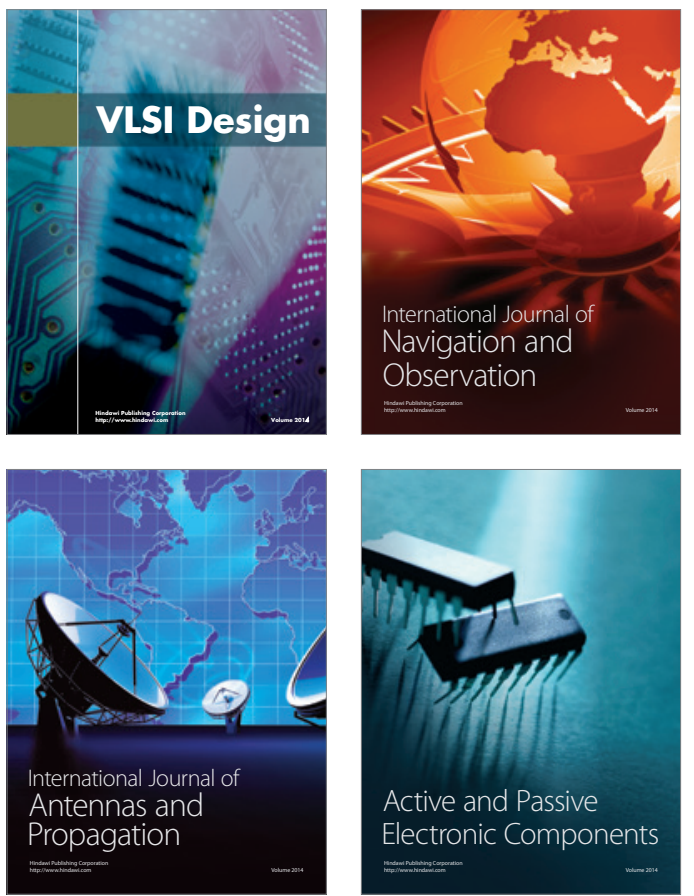
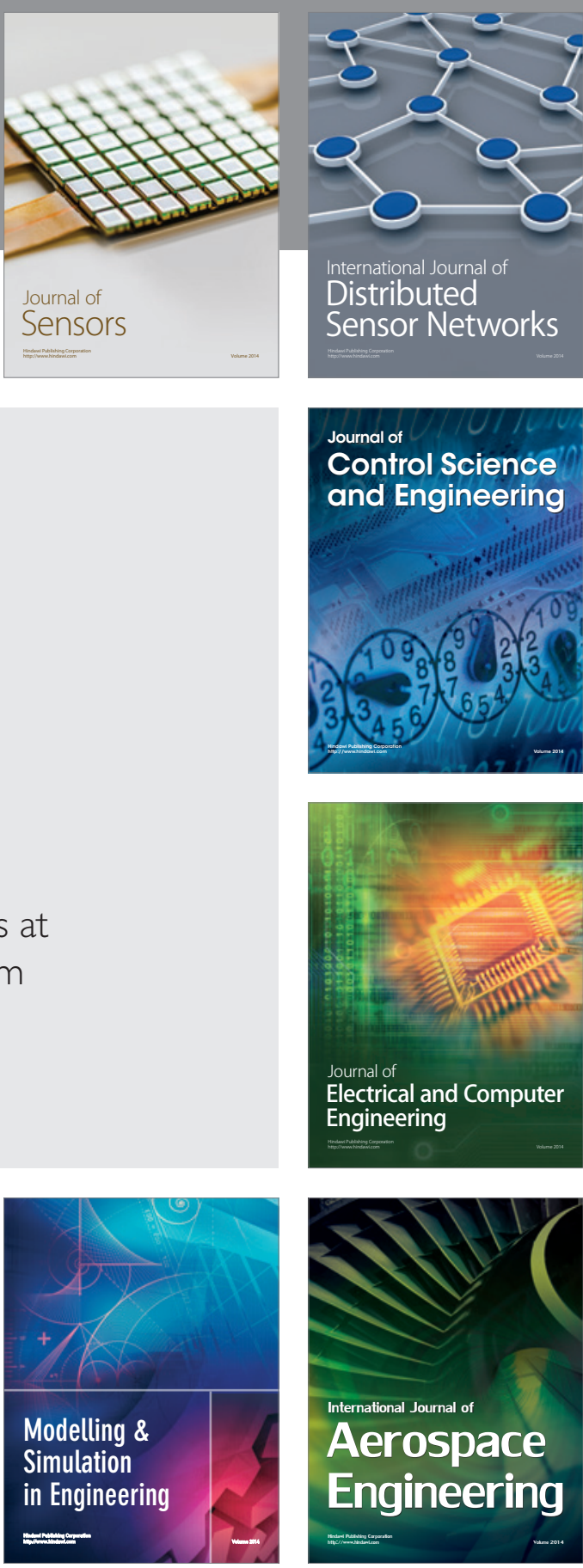

International Journal of

Distributed

Sensor Networks

Journal of

Control Science

and Engineering
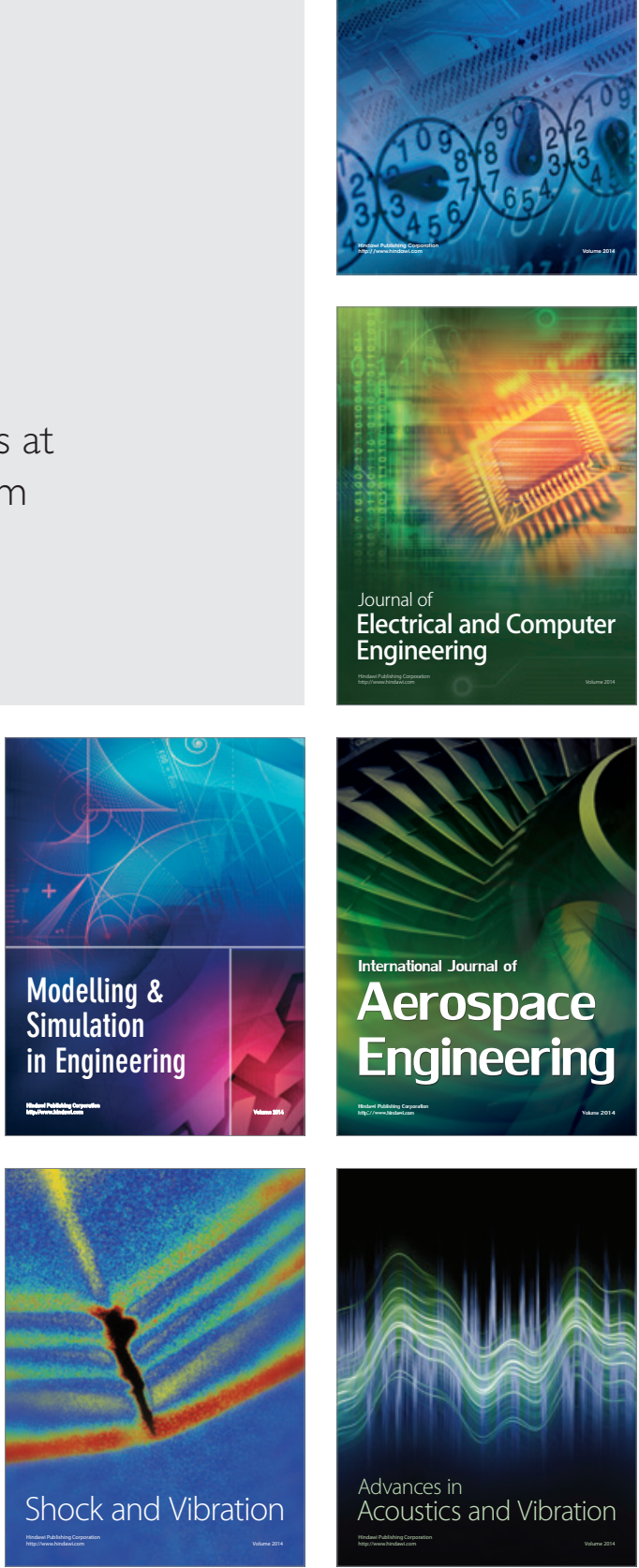